\title{
1 Fitness costs of female choosiness in a socially monogamous songbird
}

2

3 Wolfgang Forstmeier ${ }^{1 *}$, Daiping Wang ${ }^{1,2 *},{\text { Katrin } \text { Martin }^{1} \& \text { Bart Kempenaers }}^{1}$

4

51 Department of Behavioural Ecology and Evolutionary Genetics, Max Planck Institute for

6 Ornithology, Eberhard-Gwinner-Str. 7, 82319 Seewiesen, Germany

72 CAS Key Laboratory of Animal Ecology and Conservation Biology, Institute of Zoology, Chinese

8 Academy of Sciences, Beijing, China

$9 \quad *$ Address for correspondence:

Wolfgang Forstmeier*, Department of Behavioural Ecology and Evolutionary Genetics, Max Planck

11 Institute for Ornithology, Eberhard-Gwinner-Str. 7, 82319 Seewiesen, Germany, Phone: 0049-8157932346, Email: forstmeier@orn.mpg.de

Daiping Wang*, CAS Key Laboratory of Animal Ecology and Conservation Biology, Institute of Zoology, Chinese Academy of Sciences, Beijing, China, Email: wangdaiping@ioz.ac.cn

Keywords: mate choice, sexual selection, mating preferences, assortative mating, selectivity, frequency-dependent selection, zebra finch

17 Running head: Costs of choosiness

Figures \& Tables: 6 figures, 1 Table

Supplementary materials: 16 tables

20

ORCID iDs:

21 Wolfgang Forstmeier https://orcid.org/0000-0002-5984-8925

22 Daiping Wang https://orcid.org/0000-0002-9045-051X

23 Katrin Martin https://orcid.org/0000-0003-2477-8397 


\section{Abstract}

26 Female mate choice is thought to be responsible for the evolution of many extravagant male

27 ornaments and displays, but the costs of being too selective may hinder the evolution of choosiness.

28 Selection against choosiness should be strongest in socially monogamous mating systems, because

29 females may end up without a partner and forego reproduction, especially when many females

30 prefer the same few partners (frequency-dependent selection). Here we quantify the fitness costs of

31 having mating preferences that are difficult to satisfy. We capitalise on the recent discovery that

32 female zebra finches (Taeniopygia guttata) prefer males of familiar song dialect. We measured

33 female fitness in captive breeding colonies in which one third of females were given ample

34 opportunity to choose a mate of their preferred dialect (two thirds of all males; 'relaxed

35 competition'), while two thirds of the females had to compete over a limited pool of mates they

36 preferred (one third of all males; 'high competition'). As expected, social pairings were strongly

37 assortative with regard to song dialect. In the high-competition group, $26 \%$ of the females remained

38 unpaired, yet they still obtained relatively high fitness by using brood parasitism as an alternative

39 reproductive tactic. Another $31 \%$ of high-competition females paired disassortatively for song

40 dialect. These females showed increased levels of extra-pair paternity, mostly with same-dialect

41 males as sires, suggesting that preferences were not abolished after social pairing. However, females

42 that paired disassortatively for song dialect did not have lower reproductive success. Overall,

43 females in the high-competition group reached equal fitness as those that experienced relaxed

44 competition. Our study suggests that alternative reproductive tactics such as egg dumping can help

45 overcome the frequency-dependent costs of being highly selective in a monogamous mating system,

46 thereby facilitating the evolution of female choosiness. 


\section{Introduction}

Whenever organisms face multiple options to choose from (e.g. choice of food, habitat, mate) they have to weigh the potential benefits of being choosy against potential costs that arise from being too selective [1-8]. Over evolutionary time scales, the behavioural trait "choosiness" may thus evolve to an optimum level [9] or remain flexible depending on circumstances [10-14].

Female mate choice has been widely recognized as the driving force behind the evolution of many extravagant male ornaments and displays. Yet, whether such choosiness is expected to evolve should depend critically on how costly it is to be choosy. The costs of choosiness are hence central to sexual selection theory, but they have rarely been measured empirically (see below). The costs of being selective about a mate as opposed to mating with the first potential mate that is encountered will greatly depend on the species' mating system.

The most spectacular examples of sexually selected traits have been observed in lek mating systems with strong reproductive skew, i.e. systems in which most or even all females in a given area can mate with the same male. In general, females can mate with the same male if they do not seek a partner who provides non-shareable direct benefits (e.g. parental care), but only mate to obtain sperm (i.e. genetic benefits), provided sperm depletion is not an issue. Intense selection through female choice for the most attractive males should however erode genetic variation, which will then reduce the genetic benefits that females can obtain from being choosy. The apparently remaining female choosiness in face of diminishing benefits is widely known as the 'paradox of the lek', which has been addressed in numerous theoretical and empirical studies [15]. The empirical work has concentrated on quantifying (a) the costs to females of being choosy in terms of time and energy spent or in terms of predation risk [16-19], and (b) the magnitude of genetic benefits from mating with the preferred male [20]. When the costs and benefits are measured on a relevant and comparable scale, i.e. in terms of fitness consequences for the female, they appear to be so small that they can hardly be quantified with sufficient precision to provide an empirical answer to the lek paradox $[21,22]$.

Monogamous mating systems should provide a better opportunity to study the evolution of choosiness empirically, because both costs and benefits of choosiness should be much larger than in lek mating systems. In socially monogamous systems, males typically provide substantial direct benefits in the form of parental care. If the quality or quantity of parental care varies among males, females may obtain large fitness gains from selecting the best partner available [9, 23-25]. However, a female that is too selective might not find any partner that satisfies her choice criteria ("wallflower effect", [26]), especially because the best partners will rapidly disappear from the available mating 
pool. Thus, strong female competition over the best mates may lead to selection against being too choosy [27], and hence favour strategies such as accepting the first mate encountered if its quality lies within the top $80 \%$ of the males (i.e. only discriminating against the bottom $20 \%$ ). Yet, such theoretical predictions about optimal female choosiness should critically depend on behavioural tactics that females can adopt when their preferences cannot be satisfied, and on the fitness consequences of these tactics (Figure 1). This choice of tactics can be studied empirically, but we are not aware of any systematic work on this topic despite its central importance for sexual selection theory.

When many females compete for a limited number of preferred partners, they pay a cost of engaging in competition (time and energy spent in competition, risk of injury), compared to females that are not constrained by their preferences, either because their preferred partners are overabundant or because they are not choosy (Figure 1). The cost of competition can be equal for both winners and losers of the competition (as in Figure 1), but females might also vary in their abilities to avoid this cost (e.g. by 'prudent mate choice'; [12]). Females that are unsuccessful at securing a preferred partner, can either settle for a partner they do not prefer, or remain socially unpaired. In the former case, females may suffer a cost (Figure 1; see [25]) - for instance - if they are reluctant to copulate with their partner, resulting in infertility, or if they prefer to copulate with males outside the pair bond, which may lead to aggression [28] and reduced parental care by the social partner [29]. One way to avoid such costs might be to behave similarly towards a preferred and a non-preferred partner once paired. In case females remain socially unpaired, they will also pay a cost, the magnitude of which will depend on how successfully females can achieve fitness through alternative reproductive tactics, including reproduction as a single mother [30] or via brood parasitism ('egg dumping', [31-33]).

Mate choice in socially monogamous mating systems has the intriguing property that selection on mating preferences works in a negative frequency-dependent manner [34-37]. This means that the fitness consequences of an individual's preferences depend on what other individuals in the population prefer. For instance, if two thirds of all females would only accept a partner that ranks in the top third of all males (e.g. with regard to ornament size), then at least half of those females will remain unpaired, thereby lowering the mean fitness of all females that carry such preference alleles. As a consequence, such preferences will be strongly selected against, particularly when a male ornament is a poor indicator of benefits to the female [24, 37, 38]. Selection against such preferences will be strongest when the preferences are shared by most females and negative frequency dependence should finally result in relatively little consensus among females about which male is the most attractive $[36,37,39,40]$. 
115 To understand the evolution of optimal levels of choosiness in monogamous mating systems, it is

116 essential to quantify empirically the fitness costs of having preferences that are difficult to satisfy.

117 Although several studies have manipulated the costs and/or benefits of choosiness and have

118 subsequently observed female choice behaviour or mating patterns [41-47], no study to date has

119 quantified the costs in terms of female fitness.

120 One practical obstacle is that the costs of choosiness can only be measured if one finds a sufficiently

121 strong preference that will be reliably expressed by the choosing sex. In zebra finches, a socially

122 monogamous bird that forms life-long pair bonds, females reliably prefer (unfamiliar) males that

123 have learnt their song in the same population in which females grew up, over males with song from

124 a different population [48]. Working with four independent captive populations (two domesticated

125 and two recently wild-derived), we used cross-fostering of eggs between populations to produce

126 two different cultural lineages ( $A$ and $B$ ) within each population that differ only in their song dialects.

127 The lineages were bred in isolation for one additional generation, to obtain birds from the same

128 genetic population that differ only in the song that the foster-grandparents once transmitted to the

129 parents of the current generation. When bringing together equal numbers of unfamiliar males and

130 females of the two song dialects $A$ and $B$, on average $73 \%$ of pairs formed assortatively by dialect

131 (random expectation: 50\%, [48]). We made use of this moderately strong assortative mating

132 preference to design an experimental study with pre-registered methods of data collection and

133 analysis plan (https://osf.io/8md3h), ensuring maximal objectivity in the quantification of fitness

134 costs of choosiness.

135 We set up a total of 10 experimental aviaries (two or three per genetic population). In each aviary

136 we placed unequal numbers of males and females from lineages $A$ and B (e.g. 4 females of lineage $A$

137 and 8 females of $B$, facing 8 males of $A$ and 4 males of $B$ ). In this way, we created groups of females

138 that have either plenty of preferred males to choose from ('relaxed competition') or that have to

139 compete for a limited pool of preferred mates ('high competition'). The latter group can thus accept

140 a non-preferred mate (i.e. mate disassortatively) or forego forming a pair to reproduce (Figure 1).

141 This design mimics the above-described example of a two-third majority preferring a male from the

142 top third, while the other group of females are nearly unconstrained by their preference, and it

143 mirrors the principle of negative frequency dependence of preferences in a monogamous system.

144 The treatment thus alters the cost of preferring the same lineage, while the benefits of having that

145 preference should equal zero for both treatment groups (as we assumed in Figure 1, which

146 otherwise can be adapted to accommodate variation in benefits). 
147 We allowed all birds to reproduce freely for a fixed period (70 days for egg laying plus 50 days for 148 chick rearing) and quantified the fitness costs of choosiness, closely adhering to the preregistered 149 plan (https://osf.io/8md3h). Prior to data collection, we had hypothesized that (1) females from the 150 high-competition treatment will achieve lower relative fitness (measured as the number of 151 independent offspring; primary outcome) compared to the females from the relaxed-competition 152 treatment. Further we hypothesised that these females (2) will lay fewer eggs, and (3) will start egg153 laying later (secondary outcome measures). We further present the results of an unplanned, 154 exploratory part of data analysis to elucidate mechanisms by which females coped with the 155 experimental challenge (see Figure 1).

\section{Results}

\section{A. Preregistered analyses: costs of choosiness}

158 The 120 experimental females produced a total of 556 offspring that reached independence (mean 159 offspring per female $\pm S D=4.6 \pm 3.0$, range $0-13$ ). As expected, relative fitness of females 160 decreased with their inbreeding coefficient (mean $F \pm S D=0.051 \pm 0.050$, range: $0-0.28 ; p=0.006$, 161 S1 Table, model 1a). However, in contrast to our a priori prediction, the 80 females in the high162 competition treatment achieved a non-significantly higher (rather than lower) relative fitness (1.022 $\pm 0.069)$ compared to the 40 females in the relaxed-competition treatment $(0.955 \pm 0.097 ; p=0.57$; Figure 2, Table 1, model 1a, S1 Table). This result did not change after additionally controlling for additive genetic and early environmental effects on fitness (S1 Table, model 1b). Moreover, and also in contrast to our predictions, females from the high-competition treatment did not lay fewer eggs $(9.2 \pm 0.4)$ than females from the relaxed-competition group $(8.6 \pm 0.6 ; p=0.37$; Table 1 , model $2, S 2$ Table) and they did not start egg-laying later (back-transformed means, high-competition: 7.8 days after the start of the experiment, inter-quartile range: 5 - 10.5 days; relaxed-competition: 8.2 days, inter-quartile range: $5-10.5$ days; $p=0.63$; Table 1 , model 3, S3 Table).

\section{B. Post-hoc data exploration: female coping tactics}

172 The lack of significant treatment effects could be due either to a failed treatment (e.g. because birds 173 did not prefer their natal song dialect) or to female behaviour that reduces the costs of being 174 choosy. Hence, we first examined the efficiency of the treatment, i.e. the degree of assortative 175 mating by song dialect. Second, we investigated the mechanisms by which females reproduced, i.e. 176 we compared success and timing of social pairing, alternative reproductive tactics, and rearing 177 success between the two treatment groups. 
178 The degree of assortative mating, i.e. the proportion of assortative pairs, can range from zero to one

179 (see Figure 3). In our experimental setup, a value of zero can theoretically be reached if all pairs

180 mated disassortatively (zero assortative and up to 12 disassortative pairs in each aviary). A value of

181 one, corresponding to perfect assortative pairing, can only be reached if four females per aviary

182 remained unpaired (8 assortative and zero disassortative pairs per aviary). Under random pairing,

$18344.4 \%$ of pairings should be assortative ( $1 / 3$ of females has a $2 / 3$ chance of pairing assortatively, plus

$1842 / 3$ of females has a $1 / 3$ probability; $1 / 3 \times 2 / 3+2 / 3 \times 1 / 3=4 / 9$ ). If all females would attempt to pair

185 assortatively, but no female would forego pairing, $66.7 \%$ of pairings should be assortative (8

186 assortative and 4 disassortative pairs per aviary).

187 Of the 106 social pairs that were observed, 72 (67.9\%) were assortative. This significantly deviates

188 from the random expectation of $44.4 \%$ (exact goodness-of-fit test $p<0.0001$ ). Considering the

189 number of eggs in the nests of those pairs ( $N=1,022$ in total), 730 eggs (71.4\%) were cared for by

190 assortative pairs. At the genetic level, out of the 1,074 eggs fertilized and genotyped, 783 (72.9\%)

191 had parents that mated assortatively for song dialect. Hence, both at the social and genetic level, we

192 found strong assortative mating, slightly exceeding the 66.7\% "assortative if possible" threshold

193 (Figure 3).

194 Females from the two treatment groups differed significantly in their pairing success, with only 4

195 females (10\%) from the relaxed-competition treatment remaining unpaired, but 21 females (26\%)

196 from the high-competition treatment not observed in a social bond ( $p=0.03$, Figure 4A, B, Table 1,

197 model 4, S4 Table). In the relaxed-competition group, $87.5 \%$ of females $(\mathrm{N}=35)$ mated assortatively

198 with a male from their natal dialect, and one female (2.5\%) was observed in two pair bonds (one

199 assortative, one disassortative; "mixed" in Figure 4A). In contrast, in the high-competition group,

200 only $37.5 \%$ of females $(N=30)$ mated exclusively assortatively, $5 \%(N=4$ females) participated in

201 both types of pairing, and 31\% ( $N=25$ females) mated exclusively disassortatively (Figure 4B, Table

202 1, models 5-7, S5 Table, S6 Table, S7 Table).

203 Females from the high-competition group took longer to start a social bond compared to females

204 from the relaxed-competition group ( $p=0.008$, Figure $4 C$, D, Table 1, model 8 , S8 Table). For this

205 test, we assigned a maximum latency of 75 days to unpaired females (as in the pre-registered model

2063 ), because we cannot exclude that such females would have paired after a longer period. If

207 unpaired females are excluded from the analysis, the difference between treatment groups in

208 latency to pair is no longer significant $(t=1.24, p=0.22)$. Hence, the treatment prevented or delayed

209 social pairing (Table 1, models 4 and 8, S4 Table, S8 Table), but it did not prevent or delay egg-laying

210 (S2 Table, S3 Table). 
211 In 18 cases, females attempted to rear offspring as single mothers (14 females attended one clutch

212 and two females each attended two consecutive clutches). Of those, 11 clutches (61\%) were reared

213 by females that remained unpaired until the end of the experiment (overall, 25 out of 120 females

214 remained unpaired until the end, 21\%). However, the average number of clutches attended to as

215 unpaired female did not differ significantly between the treatment groups (Table 1, model 9, S9

216 Table). Females from the high-competition group on average laid fewer eggs that they actively took

217 care of, although this was not significant $(p=0.21$, Table 1 , model 10 , S10 Table). However, females

218 from the high-competition group laid significantly more eggs into clutches that were cared for by

219 other females (egg dumping in the strict sense; $p=0.038$, Table 1 , model 11, S11 Table) and into

220 nests of other females, nests attended by single males, or into unattended nest boxes (egg dumping

221 in the wide sense; $p=0.009$, Table 1 , model 12, S12 Table). Hence the proportion of parasitic eggs

222 among the total number of eggs laid was markedly higher in the high-competition than in the

223 relaxed-competition group (Table 1, models 13 and 14, S13 Table, S14 Table).

Splitting the females of each treatment group into subsets according to their social pairing status

(Figure 4) shows that the parasitic egg-dumping tactic was used more often by the unpaired females of the high-competition group (compared to relaxed-competition group; t-test with unequal variances, $\left.\mathrm{t}_{26.4}=3.37, \mathrm{p}=0.002\right)$, followed by the disassortatively mated females of the highcompetition group $\left(t_{33.4}=2.09, p=0.044\right.$; Figure $\left.5 B\right)$. Overall, females from the high-competition group achieved similar fitness as the females from the relaxed-competition group (Figure 5A), because rearing success (the proportion of fertile eggs that became independent offspring) did not differ between the treatment groups (Table 1, model 15, S15 Table).

Finally, we examined levels of extra-pair paternity in the different treatment groups, focusing on the 84 females that were socially paired to only one partner. As expected, extra-pair paternity was more frequent in the disassortatively paired females from the high-competition group (44\%, 81 out of 183 eggs from 21 females) than in the assortatively paired females from the same treatment group (18\%, 42 of 252 eggs from 27 females; $t$-test based on proportions for each female: $t_{46}=3.2, p=0.002$; Figure 6). Assortatively paired females from the relaxed-competition group showed intermediate levels of extra-pair paternity (36\%, 112 of 312 eggs from 35 females; for additional details see S16 Table). In each of the three groups, the majority of extra-pair eggs were sired assortatively $(70 \%$, $65 \%$, and $89 \%$ respectively) and all three numbers clearly exceed the corresponding random expectations ( $36 \%, 27 \%$, and $64 \%$, respectively) calculated from the number of potential extra-pair 
245 Our study illustrates the importance of empirically quantifying the costs and benefits of choosiness

246 to predict selection on the level of choosiness. This can then inform about the expected intensity of

247 sexual selection through female choice. A recent theoretical study highlighted that choosiness in

248 monogamous systems may have high costs and hence will be selected against [27]. Based on this

249 study, we hypothesized that females in the high-competition group would suffer substantial fitness

250 costs compared to the relaxed-competition group (https://osf.io/8md3h). However, our empirical

251 findings strongly suggest that female zebra finches have evolved sufficient behavioural flexibility to

252 cope with the challenge of having preferences that are difficult to satisfy such that they did not

253 suffer lower fitness. This flexibility is not trivial, because zebra finches that were force-paired

254 suffered significant fitness costs compared to birds that were allowed to choose their mate [25].

Females in the high-competition treatment on average achieved slightly higher relative fitness compared to those in the relaxed-competition group. Thus, the best estimate for the fitness cost of choosiness in our study equals zero. However, when considering reduced pairing success, delayed pairing and reliance on conditional parasitism, one could argue that the biologically most likely fitness cost is small, but positive. Females that relied on the parasitic tactic of egg dumping [31-33] were surprisingly successful in terms of fitness (Figure 5). However, our models on the use of this tactic also suggest that this may be a form of 'making the best of a bad job', because the proportion of a female's eggs that was dumped (in the wide sense) rather than actively cared for was higher in the high-competition treatment group, and also increased with the inbreeding coefficient of the female ( $p=0.002$, S14 Table). These results suggest that the parasitic tactic is associated with poor pairing success and with poor female condition. Hence, overall, there likely is a small net cost of having preferences that are hard to satisfy, but quantifying such a small cost is difficult because of sampling noise.

Our study suggests that an alternative reproductive tactic, namely egg dumping, may be important to consider as a mechanism that effectively reduces the costs of choosiness and thereby favors the evolution of choosiness even in monogamous mating systems. Alternative reproductive tactics can thereby increase the intensity of sexual selection through female choice. Note that our analysis of egg dumping is part of the post hoc data exploration rather than pre-registered hypothesis testing, which implies that the probability that this result is a chance finding is higher (Figure 5). Nevertheless, we avoided extensive exploratory testing combined with selective reporting and posthoc modification of analysis strategy to minimize the risks of false positive findings [49]. Accordingly, 
277 version. The considered hypotheses all directly follow from the observation of equal fitness in both

278 treatment groups, and address the question how females in the high-competition group responded

279 to the given mating opportunities.

280 This study also contributes to our understanding of zebra finch mating preferences with regard to 281 song dialects. Firstly, we confirmed that such preferences exist and that they are sufficiently strong

282 to result in a high degree of assortment even when bringing together unequal numbers of males and 283 females of each dialect. Secondly, assortative mating was present both at the genetic level $(72.9 \%$ of 284 fertilized eggs had assortative genetic parents) and at the social level (71.4\% of eggs were cared for 285 by assortative pairs). As $78.2 \%$ of all eggs sired by extra-pair males were assortative, we infer that 286 song dialect preferences affect both social pairing and extra-pair mate choice.

The possible adaptive function of these preferences in the wild is not known. They could function to enhance local mating to obtain locally adapted genes, which would be adaptive in both the social and extra-pair context. However, this possibility seems unlikely in light of the lack of genetic differentiation even over a large geographic distance [50]. More widespread sampling of genotypes throughout Australia would be required to rule out this possibility. Alternatively, song preferences could function to find a mate that hatched locally $[51,52]$ and hence may have gathered local information on ecologically relevant factors such as resources and predation risk. In that case, the song preferences during extra-pair mating might represent a (non-adaptive) spill-over of preferences that are functional in social pairing, or extra-pair mating could function to maintain additional social bonds with similar direct benefits (Maldonado-Chaparro et al. 2018).

297 Our study was designed to estimate the costs of female choosiness, whereby we predicted that these costs would be high in a monogamous mating system [27]. However, this is not what we found. Our study did not fail in the sense that our treatment was effective (Figs. 2 and 3), but females were sufficiently flexible to not suffer substantial fitness costs under high competition for preferred males, at least in our aviary setting. Thus, our study does not support the hypothesis that female choosiness is costly in a socially monogamous system. Females from the high-competition treatment were affected in terms of delayed pairing and reduced pairing success, but they made up for this primarily by the alternative reproductive tactic of egg dumping and only rarely by caring for clutches as a single mother. Females who ended up paired with a non-preferred partner, were more likely to engage in extra-pair copulations, but this did not affect their fitness (see Fig. 4). This stands in contrast to an earlier study that showed that force-paired females responded more negatively to 
in a significant reduction in fitness [25]. Overall, these results emphasize that models on the costs of choosiness need to be informed by empirical research.

\section{Methods}

All methods closely adhere to the pre-registration document (https://osf.io/8md3h), except for the exploratory post-hoc analyses (presented below).

\section{Ethics}

The study was carried out under the housing and breeding permit no. 311.4-si (by Landratsamt Starnberg, Germany) which covers all procedures implemented (including the obtaining of one blood sample per individual for parentage assignment).

\section{Background of study populations and assortative mating}

The zebra finches used in this study originate from four captive populations maintained at the Max Planck Institute for Ornithology: two domesticated (referred to as 'Seewiesen' (S) and 'Krakow' (K)) and two recently wild-derived populations ('Bielefeld' (B) and 'Melbourne' (M)). For more background and general housing conditions see $[25,53,54]$. The four populations have been maintained in separate aviaries (without visual and with limited auditory contact). When birds from two different populations (combining $S$ with $B$, and $K$ with $M$ ) were brought together in the same breeding aviary, they formed social pairs that were predominantly assortative with regard to population (87\% assortative pairs), despite the fact that opposite-sex individuals were unfamiliar with each other ([48], see also [55]). To find out whether this assortative mating took place because of genetic (e.g. body size) or cultural (e.g. song) differences, we produced an offspring generation ('F1') in which half of the birds were cross-fostered between populations (between $S$ and $B$, or between $\mathrm{K}$ and $\mathrm{M}$ ) and half of the birds were cross-fostered within populations. For this purpose, we used 16 aviaries (4 per population), each containing 8 males and 8 females of the same population that were allowed to freely form pairs and breed. Cross-fostering was carried out at the aviary level, such that 2 aviaries per population served for cross-fostering within population and the other 2 for between-population cross-fostering. This resulted in 8 cultural lines (4 populations $\times 2$ song dialects), each maintained in 2 separate aviaries (16 aviaries). When unfamiliar individuals of the two song dialects were brought together in equal numbers (50:50 sex ratio), they mated assortatively regarding song (79\% assortative pairs; Wang et al. 2020) but not regarding genetic population. To disentangle the song effect of interest from possible side-effects of the cross-fostering per se, the 8 lines were bred for one more generation ('F2'). These F2 individuals are the focal subjects of this study. Breeding took place in 16 aviaries ( 2 per song dialect within population), but without cross- 
341 fostering. The two replicate aviaries of each song dialect line each contained 8 males and 8 females

342 that produced the next generation. A subset of the resulting offspring $(n=144$, not used in this

343 study, but see below) were used to test mate choice within each of the 4 genetic populations (here

344 referred to as 'F2 pilot experiment'). Again, we observed assortative pairing for song dialect (73\%

345 assortative pairs). The remaining F2 offspring were used as candidates for the experiment, as

346 explained below.

347 Experimental setup

348 To quantify the female fitness consequences of having preferences for males that are either rare or 349 overabundant, we used 10 aviaries ( 3 for populations $B$ and $K$, and 2 for populations $\mathrm{S}$ and $\mathrm{M}$ ). Each

350 semi-outdoor aviary (measuring $4 \mathrm{~m} \times 5 \mathrm{~m} \times 2.5 \mathrm{~m}$ ) contained 12 males and 12 females of the same

351 genetic population, but from two different song dialects such that 4 females encountered 8 males of

352 the same dialect, while the remaining 8 females encountered only 4 males of their own dialect.

353 Hence, for each experimental aviary, we used individuals that were raised in 4 separate aviaries (2 of

354 each song dialect) to ensure that opposite-sex individuals were unfamiliar to each other.

355 The allocation of birds to the aviaries followed two principles. First, we listed for each of the 16

356 rearing aviaries the number of available female and male F2 offspring that had not been used

357 previously (in the ' $F 2$ pilot experiment') and that were apparently healthy ( 374 birds). Depending on

358 the number of available birds, each rearing aviary was then designated to provide either 4 or 8 birds

359 of either sex, such that the total number of experimental breeding aviaries that could be set up was

360 maximized (10 aviaries). Second, the allocation of the available individuals within each rearing aviary

361 to the designated groups of 4 or 8 individuals of a given sex was decided by Excel-generated random

362 numbers. For instance, if a given rearing aviary had 17 candidate female offspring, individuals were

363 randomly allocated to a group of 4 for one experimental aviary, a group of 8 for another aviary, and

364 a group of 5 as leftover (not used). This allocation procedure may have introduced a bias, because

365 rearing aviaries that were highly productive (had more offspring) were more frequently designated

366 to send groups of 8 offspring to an experimental aviary, while those that produced fewer offspring

367 (in the extreme case fewer than 8 of one sex) were more likely used to send a group of 4 offspring to

368 an experimental aviary. This might bias our fitness estimates if offspring production was partly

369 heritable or if housing density prior to the experiment influenced the fitness in the experimental

370 aviaries. We therefore assessed these potential biases in the statistical analysis (see model $1 \mathrm{~b}$

371 below).

372 After allocating individuals to the 10 experimental aviaries, one female (designated for aviary 2 ) and

373 two males (designated for aviary 3 ) died before the start of the experiment. These individuals were 
374 then replaced by randomly choosing individuals of the same sex and rearing aviary, which however

375 had previously taken part in the 'F2 pilot experiment' (17-30 January 2019). These replacement birds

376 differed from the other individuals in the experiment, in that they had previous experience of nest-

377 building and egg-laying $>100$ days before the start of experiment.

378 The 120 focal females had hatched in one of the 16 natal aviaries between 30 May and 25

379 September 2018 and remained in their natal aviaries initially together with their parents (which 380 were removed between 10 December 2018 and 16 January 2019). On 6 May 2019, all individuals

381 used in the experiment were transferred to the 10 aviaries, whereby the 12 males and 12 females in

382 each aviary were separated by an opaque divider. After one week, the divider was removed and the

383 experiment started. At this time, females were on average 313 days old (range: 230 - 348 days). To

384 facilitate individual identification, each of the 12 males and 12 females within each aviary was

385 randomly assigned two coloured leg bands (using the following 12 combinations: blue-blue, black-

386 black, orange-orange, orange-black, red-red, red-blue, red-black, white-white, white-black, white-

387 orange, yellow-yellow, yellow-blue).

388 Breeding procedures

389 Each of the 10 experimental aviaries was equipped with 14 nest boxes. All nest boxes were checked daily during week days (Mon-Fri) for the presence of eggs or offspring. Eggs and offspring were individually marked and a note was made whether eggs were warm. For eggs laid on weekends, we estimated the most likely laying date based on egg development. We collected a DNA sample from all fertilized eggs (including naturally died embryos and nestlings), unless they disappeared before sampling (see below) to determine parentage. Eggs containing naturally died embryos ( $N=343$ ) were collected and replaced by plastic dummy eggs (on average $12 \pm 4$ (SD) days after laying and $7 \pm$ 4 days after estimated embryo death). Eggs that remained cold (unincubated) for 10 days ( $N=7$ out of 1,399 eggs) were removed without replacement and were incubated artificially to identify parentage from embryonic tissue. During nest checks we noted the identity of the parent(s) that attended the nest (based on colour bands) to clarify nest ownership for all clutches that were incubated.

As the main response variable, we quantified the reproductive success ('fitness') of each female in each experimental aviary as the total number of genetic offspring produced that reached the age of 35 days (typical age of independence). All eggs laid within a period of 70 days (between 13 May and 22 July 2019; $N=1,399$ ) were allowed to be reared to independence; eggs laid after this period were thrown away and replaced by plastic dummy eggs to terminate a breeding episode without too much disturbance. 
407 Out of 1,399 eggs, 319 eggs failed (180 appeared infertile, 101 disappeared, 30 broke, 4 had

408 insufficient DNA, 3 eggs showed only paternal alleles (androgenesis), 1 sample was lost). For the

409 remaining 1,080 eggs we unambiguously assigned maternity and paternity based on 15

410 microsatellite markers (for details see Wang et al. 2017). Of these 1,080 fertile eggs, 750 developed

411 into nestlings and 556 into offspring that reached 35 days of age.

412 The 1,399 eggs were distributed over 289 clutches (allowing for laying gaps of maximally 4 days), of

413 which 190 (1,022 eggs) were attended by a heterosexual pair (involving 106 unique pairs), 55 (120

414 eggs) remained unattended, 24 (120 eggs) were attended by a single female, 12 (41 eggs) were

415 attended by a single male, 3 (36 eggs) were attended by a female-female pair, 2 (30 eggs) were

416 attended by two males and two females, 2 (21 eggs) were attended by a trio with two females, and 1

417 (9 eggs) by a trio with two males.

418 We also quantified two additional response variables for every female, namely the latency to start

419 laying eggs (in days since the start of the experiment, counting to the first recorded fertile egg, and

420 ascribing a latency of 75 days to females without fertile eggs) and the total number of fertile eggs

421 laid within the 70-day experimental period (both based on the 1,080 eggs with genetically confirmed

422 maternity). The 319 failed eggs were not considered.

423 Over the course of the experiment (13 May to 22 July 22 for egg laying and until 9 September for

424 rearing young to independence) one male and two females (all of the more abundant type within

425 their aviaries) died of natural causes (a male in aviary 5 on 28 June, a female in aviary 6 on 24 July,

426 and a female in aviary 10 on 22 August). Thus, following the preregistered protocol, no bird was

427 excluded from data analysis.

428 Data analysis

429 Following previously used methods [25, 56], we calculated 'relative fitness' for each female as

430 relative fitness of female $\mathrm{i}=\mathrm{N} *$ number of offspring of female $\mathrm{i} /$ total number of offspring of all $\mathrm{N}$

431 females in the aviary. This index has a mean of 1 for each aviary, and accounts for fitness differences

432 between the 4 genetic populations (note that all birds within an aviary come from the same genetic

433 population). Latency to egg laying was log10-transformed before analysis to approach normality. To

434 control for the effect of inbreeding on fitness, we calculated female inbreeding coefficients $F$ from

435 existing genetic pedigree data (using the R package 'pedigree' V.1.4, [57]). All mixed effect models

436 were built with the R package 'Ime4' V1.1-26 [58] in R version 4.0.3 [59] and p-values were

437 calculated from $t$-values assuming infinite degrees of freedom. 
438 Table 1 lists all the statistical models that compare the two treatment groups. These comprise both

439 pre-registered models (1-3) and post-hoc exploratory models (4-15). All models have the same basic

440 structure comparing a fitness-related trait between the two treatment groups (120 rows of data

441 representing 80 high-competition and 40 relaxed-competition females). Thus, we used mixed-effect

442 models with Gaussian (models 1-12) or binomial (models 13-15) errors, with the fitness-related trait

443 as the dependent variable, with treatment as the fixed effect of interest, with a scaled inbreeding

444 coefficient of the female as a covariate, and with the experimental aviary (10 levels) and the natal

445 aviary (16 levels) as random effects.

446 For preregistered model 1 we ran two versions (1a and $1 b$ ). Because the dependent variable of this

447 model is relative fitness, which was scaled within experimental aviaries, the model was designed

448 without random effects (as a general linear model, 1a). To control for possible influences of the natal

449 environment and of the genetic F1 mother we added two fixed-effect covariates (in version 1b): (1)

450 the total number of F2 offspring in the natal aviary where the focal female was raised (ranging from

45129 to 45 offspring across the 16 natal aviaries), (2) the number of independent F2 offspring produced

452 by the genetic mother (one year earlier, also within a 70-day window for egg-laying; mean: 5.7,

453 range: $0-12, \mathrm{~N}=66$ mothers of the 120 focal females).

\section{Exploratory analyses}

455 To quantify the extent of assortative mating with regard to song dialect at the behavioural level, we

456 relied on the 106 unique heterosexual pairs that were observed caring for at least one of 190

457 clutches (comprising 1,022 eggs). For the quantification of assortment on the genetic level, we relied

458 on the genetic parentage of the 1,080 successfully genotyped eggs, of which 6 eggs had to be

459 excluded because they were sired by males from the females' natal aviaries (due to sperm storage, $\mathrm{N}$

$460=4$ ), because alleles from two males were detected (presumably due to polyspermy, $N=1$ ), or

461 because no paternal alleles were detected (possible case of parthenogenesis, $N=1$ ), leaving 1,074

462 informative eggs.

463 For each female, we scored their social pairing behaviour, i.e. we noted whether they had been

464 recorded as a member of one of the 106 heterosexual pairs engaging in brood care. We quantified

465 (a) the total number of social bonds $(0,1$, or 2$)$, (b) the number of assortative and disassortative

466 bonds and (c) the latency to their first social bond (i.e. the laying date of the first egg in a clutch they

467 attended as one of the 106 pairs, relative to the start of the experiment; ascribing a latency of 75

468 days to females with zero social bonds). Latency was log10-transformed before analysis. 
For each female, we also counted the number of clutches $(0,1$, or 2$)$ attended as a single mother and we quantified (a) the number of eggs (out of the 1,080 genetically assigned eggs) they actively cared for themselves (in whatever social constellation), (b) the number of eggs dumped into nests attended by other females (in whatever social constellation, "egg dumping in the strict sense") and (c) the number of eggs dumped anywhere ("egg dumping in the wide sense", including in nests

474 attended by single males and in unattended nest boxes). All exploratory mixed-effect models (4-15) closely follow the design of the preregistered models 2 and 3 (see above). successes and failures, and controlling for overdispersion by fitting female identity (120 levels) as another random effect.

We ran exploratory analyses on the levels of extra-pair paternity of 84 females that were socially paired to only a single male (i.e. recorded with only one male, among the 106 nest-attending heterosexual pairs). These 84 females produced a total of 795 eggs with parentage information. However, we excluded 48 eggs (from 16 females) that were laid before the date of pairing of the focal female (genetic mother). Overall, 239 of the remaining 747 eggs (32\%) were sired by a male that was not the social partner (the male with whom the female attended a nest), so these are classified as 'extra-pair sired'. We calculated levels of extra-pair paternity for three groups of females: (1) assortatively paired females of the relaxed-competition group ( $n=35$ females), ( 2 ) assortatively paired females of the high-competition group ( $n=28$ females, one of which did not lay any eggs with parentage information), (3) disassortatively paired females of the high-competition group ( $\mathrm{n}=21$ females). To compare levels of extra-pair paternity between the latter two groups of females, we used a t-test on percentages of extra-pair paternity calculated for each female.

\section{Acknowledgments}

493 We are grateful to M. Schneider for molecular work and to E. Bodendorfer, J. Didsbury, P. Neubauer, 494 C. Scheicher, I. Schmelcher, and B. Wörle for animal care.

\section{Authors' contributions}

496 WF, DW and BK conceived the study. KM carried out the study and collected the data. WF analyzed 497 and interpreted the data with inputs from BK. WF and BK wrote the manuscript with input from DW. 
This research was supported by the Max Planck Society (to BK).

\section{Data accessibility}

504 All underlying data can be found on the Open Science Framework under

505

https://osf.io/6e8np

\section{References} choosing feel like losing. Journal of Consumer research. 2003;30(1):15-29.

2. Huffman C, Kahn BE. Variety for sale: Mass customization or mass confusion? Journal of retailing. 1998;74(4):491-513.

513 3. Jaumann S, Snell-Rood EC. Trade-offs between fecundity and choosiness in ovipositing 514 butterflies. Animal Behaviour. 2017;123:433-40.

515 4. Jayasingam S, Fujiwara Y, Thurasamy R. 'I am competent so I can be choosy': choosiness and 516 its implication on graduate employability. Studies in Higher Education. 2018;43(7):1119-34.

517 5. Mick DG, Broniarczyk SM, Haidt J. Choose, choose, choose, choose, choose, choose, choose: 518 Emerging and prospective research on the deleterious effects of living in consumer hyperchoice. 519 Journal of Business Ethics. 2004;52(2):207-11.

5206 6eal L. Search theory and mate choice. I. Models of single-sex discrimination. The American 521 Naturalist. 1990;136(3):376-405.

$5227 . \quad$ Schwartz B. Navigating the paradox of choice. International Commerce Review: ECR Journal. 523 2006;6(1):43.

524 8. Stamps JA, Krishnan V, Reid ML. Search costs and habitat selection by dispersers. Ecology. $525 \quad 2005 ; 86(2): 510-8$.

526 9. Etienne L, Rousset F, Godelle B, Courtiol A. How choosy should I be? The relative searching 527 time predicts evolution of choosiness under direct sexual selection. Proceedings of the Royal Society 528 B: Biological Sciences. 2014;281(1785):20140190.

529 10. Candolin U, Salesto T. Does competition allow male mate choosiness in threespine 530 sticklebacks? The American Naturalist. 2009;173(2):273-7.

531 11. Cotton S, Small J, Pomiankowski A. Sexual selection and condition-dependent mate 532 preferences. Current Biology. 2006;16(17):R755-R65.

533 12. Härdling R, Kokko H. The evolution of prudent choice. Evolutionary Ecology Research. 534 2005;7(5):697-715.

535 13. Moore PJ, Moore AJ. Reproductive aging and mating: the ticking of the biological clock in 536 female cockroaches. Proceedings of the National Academy of Sciences. 2001;98(16):9171-6.

537 14. Chevalier L, Labonne J, Galipaud M, Dechaume-Moncharmont F-X. Fluctuating dynamics of 538 mate availability promote the evolution of flexible choosiness in both sexes. The American 539 Naturalist. 2020;196(6):730-42.

540 15. Kotiaho JS, LeBas NR, Puurtinen M, Tomkins JL. On the resolution of the lek paradox. Trends 541 in ecology \& evolution. 2008;23(1):1-3. 
542 16. Alem S, Greenfield MD. Economics of mate choice at leks: do female waxmoths pay costs for 543 indirect genetic benefits? Behavioral Ecology. 2010;21(3):615-25.

544 17. Byers JA, Wiseman PA, Jones L, Roffe TJ. A large cost of female mate sampling in pronghorn.

545 The American Naturalist. 2005;166(6):661-8.

546 18. Gibson RM, Bachman GC. The costs of female choice in a lekking bird. Behavioral Ecology.

547 1992;3(4):300-9.

548 19. Vitousek MN, Mitchell MA, Woakes AJ, Niemack MD, Wikelski M. High costs of female choice 549 in a lekking lizard. PLoS One. 2007;2(6):e567.

$55020 . \quad$ M $\varnothing$ ller AP, Alatalo RV. Good-genes effects in sexual selection. Proceedings of the Royal

551 Society of London Series B: Biological Sciences. 1999;266(1414):85-91.

552 21. Charmantier A, Sheldon BC. Testing genetic models of mate choice evolution in the wild.

553 Trends in Ecology \& Evolution. 2006;21(8):417-9.

55422 . Kirkpatrick $M$, Barton $N$. The strength of indirect selection on female mating preferences.

555 Proceedings of the National Academy of Sciences. 1997;94(4):1282-6.

556 23. Hoelzer GA. The good parent process of sexual selection. Animal Behaviour.

557 1989;38(6):1067-78.

558 24. Møller A, Jennions M. How important are direct fitness benefits of sexual selection?

559 Naturwissenschaften. 2001;88(10):401-15.

560 25. Ihle $M$, Kempenaers B, Forstmeier W. Fitness benefits of mate choice for compatibility in a

561 socially monogamous species. PLoS Biol. 2015;13(9):e1002248.

562 26. Kokko H, Mappes J. Sexual selection when fertilization is not guaranteed. Evolution.

563 2005;59(9):1876-85.

564 27. Dechaume-Moncharmont F-X, Brom T, Cézilly F. Opportunity costs resulting from scramble

565 competition within the choosy sex severely impair mate choosiness. Animal Behaviour.

566 2016;114:249-60.

567 28. Valera F, Hoi H, Krištín A. Male shrikes punish unfaithful females. Behavioral Ecology.

568 2003;14(3):403-8.

569 29. Griffin AS, Alonzo SH, Cornwallis CK. Why do cuckolded males provide paternal care? PLoS

570 Biol. 2013;11(3):e1001520.

$57130 . \quad$ Møller AP. Male parental care, female reproductive success, and extrapair paternity.

572 Behavioral Ecology. 2000;11(2):161-8.

573 31. Lyon BE, Eadie JM. Conspecific brood parasitism in birds: a life-history perspective. Annual

574 Review of Ecology, Evolution, and Systematics. 2008;39:343-63.

575 32. Schielzeth $\mathrm{H}$, Bolund E. Patterns of conspecific brood parasitism in zebra finches. Animal

576 behaviour. 2010;79(6):1329-37.

577 33. Yom-Tov Y. An updated list and some comments on the occurrence of intraspecific nest

578 parasitism in birds. Ibis. 2001;143(1):133-43.

579 34. Andersson M. Sexual selection: Princeton University Press; 1994.

$580 \quad 35 . \quad K o k k o H$, Booksmythe I, Jennions MD. Mate-sampling costs and sexy sons. Journal of

581 evolutionary biology. 2015;28(1):259-66.

582 36. Vakirtzis A, Roberts SC. Nonindependent mate choice in monogamy. Behavioral Ecology. 583 2010;21(5):898-901.

$584 \quad 37$. Wang D, Forstmeier W, Kempenaers B. No mutual mate choice for quality in zebra finches:

585 Time to question a widely held assumption. Evolution. 2017;71(11):2661-76.

586 38. Wiegmann DD, Angeloni LM, Seubert SM, Gordon J. Mate choice decisions by searchers.

587 Current Zoology. 2013;59(2):184-99.

588 39. Forstmeier W, Birkhead TR. Repeatability of mate choice in the zebra finch: consistency

589 within and between females. Animal Behaviour. 2004;68(5):1017-28.

590 40. Wang D, Forstmeier W, Martin K, Wilson A, Kempenaers B. The role of genetic constraints 591 and social environment in explaining female extra-pair mating. Evolution. 2020;74(3):544-58. 
592 41. Alatalo RV, Carlson A, Lundberg A. The search cost in mate choice of the pied flycatcher.

593 Animal Behaviour. 1988;36(1):289-91.

594 42. Booksmythe I, Detto T, Backwell PR. Female fiddler crabs settle for less: the travel costs of

595 mate choice. Animal Behaviour. 2008;76(6):1775-81.

596 43. Godin J-GJ, Briggs SE. Female mate choice under predation risk in the guppy. Animal

597 Behaviour. 1996;51(1):117-30.

598 44. Hedrick AV, Dill LM. Mate choice by female crickets is influenced by predation risk. Animal

599 Behaviour. 1993.

600 45. Milinski M, Bakker TC. Costs influences sequential mate choice in sticklebacks, Gasterosteus

601 aculeatus. Proceedings of the Royal Society of London Series B: Biological Sciences.

602 1992;250(1329):229-33.

603 46. Willis PM, Ryan MJ, Rosenthal GG. Encounter rates with conspecific males influence female

604 mate choice in a naturally hybridizing fish. Behavioral Ecology. 2011;22(6):1234-40.

605 47. Wong BB, Jennions MD. Costs influence male mate choice in a freshwater fish. Proceedings

606 of the Royal Society of London Series B: Biological Sciences. 2003;270(suppl_1):S36-S8.

607 48. Wang D, Forstmeier W, Farine D, Maldonado-Chaparro A, Martin K, Pei Y, et al. Machine

608 learning reveals cryptic dialects that guide mate choice in a songbird. BioRxiv.

609 2021;doi.org/10.1101/2021.02.08.430277.

610 49. Forstmeier W, Wagenmakers EJ, Parker TH. Detecting and avoiding likely false-positive

611 findings-a practical guide. Biological Reviews. 2017;92(4):1941-68.

612 50. Forstmeier W, Segelbacher G, Mueller JC, Kempenaers B. Genetic variation and

613 differentiation in captive and wild zebra finches (Taeniopygia guttata). Molecular ecology.

614 2007;16(19):4039-50.

615 51. Runciman D, Zann RA, Murray ND. Geographic and temporal variation of the male zebra

616 finch distance call. Ethology. 2005;111(4):367-79.

617 52. Zann R. Variation in song structure within and among populations of Australian zebra

618 finches. The Auk. 1993;110(4):716-26.

619 53. Pei Y, Forstmeier W, Wang D, Martin K, Rutkowska J, Kempenaers B. Proximate causes of

620 infertility and embryo mortality in captive zebra finches. bioRxiv. 2019:847103.

621 54. Wang D, Forstmeier W, Ihle M, Khadraoui M, Jerónimo S, Martin K, et al. Irreproducible text-

622

623

624

625

626

627

628

629 book "knowledge": The effects of color bands on zebra finch fitness. Evolution. 2018;72(4):961-76.

55. Rutstein AN, Brazill-Boast J, Griffith SC. Evaluating mate choice in the zebra finch. Animal Behaviour. 2007;74(5):1277-84.

56. Jerónimo S, Khadraoui M, Wang D, Martin K, Lesku JA, Robert KA, et al. Plumage color manipulation has no effect on social dominance or fitness in zebra finches. Behavioral Ecology. 2018;29(2):459-67.

57. Coster A. pedigree: Pedigree functions. R package version 1.4. Comprehensive R Arch. Vienna: Network; 2015.

630 58. Bates D, Maechler M, Bolker B, Walker S. Fitting Linear Mixed-Effects Models Using Ime4. 631 Journal of Statistical Software. 2015;67(1):1-48. doi: doi:10.18637/jss.v067.i01.

632 59. R-Core-Team. R: A language and environment for statistical computing. Vienna, Austria: R 633 Foundation for Statistical Computing; 2020. 
637 Table 1. Comparisons between females of the 'high-competition' $(n=80)$ and 'relaxed competition'

$638(n=40)$ treatment. Overview of planned tests (models 1-3, as outlined in the pre-registration

639 document before data collection; https://osf.io/8md3h) and post-hoc tests that were conducted

640 after knowing the results of the planned tests (data exploration, models 4-15). All conducted tests

641 are reported in their initial form (no selective reporting, no post-hoc modification). Indicated are

642 average values for the two treatment groups for each dependent variable. Proportions of eggs refer

643 to means of individual mean proportions. For latencies, back-transformed values after averaging

$644 \log _{10}$-transformed values are shown. P-values refer to group differences based on glms or glmms.

645 Covariates are the female's inbreeding coefficient (F), the size of the peer group in the female's natal

646 aviary (peersize), and the fitness of the female's mother. Random effects are the experimental aviary

647 (exp AV, 10 levels), the female's natal aviary (natal AV, 16 levels), and - in binomial models of counts

648 with overdispersion - female identity (FID, 120 levels) (see S1-S15 Tables for details). Note that the

649 high significance of the treatment effect in models 6 and 7 is partly caused by the experimental

650 design.

\begin{tabular}{|c|c|c|c|c|c|c|c|c|}
\hline Model & Test type & Dependent variable & $\begin{array}{c}\text { High } \\
\text { competition }\end{array}$ & $\begin{array}{l}\text { Relaxed } \\
\text { competition }\end{array}$ & $\begin{array}{c}p \\
\text { (treatment) }\end{array}$ & $\begin{array}{l}\text { Trend in } \\
\text { expected } \\
\text { direction }\end{array}$ & Covariates & $\begin{array}{l}\text { Random } \\
\text { effects }\end{array}$ \\
\hline $1 a$ & planned & $\begin{array}{l}\text { relative fitness } \\
\text { (scaled to unity) }\end{array}$ & 1.023 & 0.953 & 0.57 & no & $\mathrm{F}$ & - \\
\hline $1 b$ & planned & $\begin{array}{l}\text { relative fitness } \\
\text { (scaled to unity) }\end{array}$ & 1.023 & 0.953 & 0.32 & no & $\begin{array}{l}\text { F, peersize, } \\
\text { mother fitness }\end{array}$ & - \\
\hline 2 & planned & $\mathrm{N}$ genetic eggs laid & 9.21 & 8.58 & 0.37 & no & $\mathrm{F}$ & $\begin{array}{l}\exp A V \text {, } \\
\text { natal } A V\end{array}$ \\
\hline 3 & planned & $\begin{array}{l}\text { latency to first } \\
\text { genetic egg (days) }\end{array}$ & 7.78 & 8.25 & 0.63 & no & $\mathrm{F}$ & $\begin{array}{l}\exp A V \text {, } \\
\text { natal } A V\end{array}$ \\
\hline 4 & exploration & $\begin{array}{l}\text { Proportion females } \\
\text { socially unpaired }\end{array}$ & $26 \%$ & $10 \%$ & 0.03 & yes & $\mathrm{F}$ & $\begin{array}{l}\exp A V \text {, } \\
\text { natal } A V\end{array}$ \\
\hline 5 & exploration & $\begin{array}{l}\mathrm{N} \text { social bonds per } \\
\text { female }\end{array}$ & 0.863 & 0.925 & 0.42 & yes & $\mathrm{F}$ & $\begin{array}{l}\exp A V \text {, } \\
\text { natal } A V\end{array}$ \\
\hline 6 & exploration & $\begin{array}{l}\mathrm{N} \text { assortative social } \\
\text { bonds }\end{array}$ & 0.450 & 0.900 & 0.000002 & yes & $\mathrm{F}$ & $\begin{array}{l}\exp A V \text {, } \\
\text { natal } A V\end{array}$ \\
\hline 7 & exploration & $\begin{array}{l}\mathrm{N} \text { disassortative } \\
\text { social bonds }\end{array}$ & 0.413 & 0.025 & 0.0014 & yes & $\mathrm{F}$ & $\begin{array}{l}\exp A V \text {, } \\
\text { natal } A V\end{array}$ \\
\hline 8 & exploration & $\begin{array}{l}\text { latency to first social } \\
\text { bond with eggs (days) }\end{array}$ & 13.48 & 7.93 & 0.008 & yes & $\mathrm{F}$ & $\begin{array}{l}\exp A V \text {, } \\
\text { natal AV }\end{array}$ \\
\hline 9 & exploration & $\begin{array}{l}\mathrm{N} \text { clutches attended } \\
\text { as a single mother }\end{array}$ & 0.163 & 0.125 & 0.57 & yes & $\mathrm{F}$ & $\begin{array}{l}\exp A V \text {, } \\
\text { natal } A V\end{array}$ \\
\hline 10 & exploration & $\begin{array}{l}\mathrm{N} \text { eggs actively taken } \\
\text { care off }\end{array}$ & 6.64 & 7.40 & 0.21 & yes & $\mathrm{F}$ & $\begin{array}{l}\exp A V \text {, } \\
\text { natal AV }\end{array}$ \\
\hline 11 & exploration & $\begin{array}{l}N \text { eggs dumped to } \\
\text { other females (strict) }\end{array}$ & 1.63 & 0.80 & 0.038 & yes & $\mathrm{F}$ & $\begin{array}{l}\exp A V \text {, } \\
\text { natal } A V\end{array}$ \\
\hline 12 & exploration & $\begin{array}{l}\mathrm{N} \text { eggs dumped } \\
\text { anywhere (wide) }\end{array}$ & 2.58 & 1.18 & 0.009 & yes & $\mathrm{F}$ & $\begin{array}{l}\exp A V \text {, } \\
\text { natal } A V\end{array}$ \\
\hline 13 & exploration & $\begin{array}{l}\text { Proportion eggs } \\
\text { dumped (strict) }\end{array}$ & $17 \%$ & $9 \%$ & 0.027 & yes & $\mathrm{F}$ & $\begin{array}{l}\exp A V, \\
\text { natal AV, } \\
\text { FID }\end{array}$ \\
\hline 14 & exploration & $\begin{array}{l}\text { Proportion eggs } \\
\text { dumped (wide) }\end{array}$ & $29 \%$ & $12 \%$ & 0.001 & yes & $\mathrm{F}$ & $\begin{array}{c}\exp A V, \\
\text { natal AV, } \\
\text { FID }\end{array}$ \\
\hline 15 & exploration & $\begin{array}{l}\text { Proportion fertile } \\
\text { eggs leading to } \\
\text { offspring }\end{array}$ & $50.1 \%$ & $50.2 \%$ & 0.87 & yes & $\mathrm{F}$ & $\begin{array}{c}\exp A V, \\
\text { natal AV, } \\
\text { FID }\end{array}$ \\
\hline
\end{tabular}


651

652

653

654

655

656

657

658

659

660

661

662

663

664

665

666

667

Figure 1. Schematic representation of the expected fitness costs of choosiness when females are limited by the availability of preferred mates (red, high competition) compared to females that are not limited by their choosiness or by the availability of preferred mates (blue, relaxed competition). For simplicity, we assume that preferred and non-preferred mates do not differentially affect female fitness. Diamonds illustrate variation in individual fitness around the mean fitness of a group of females (centre of diamonds, horizontal lines). Black arrows stand for various aspects of costs of choosiness under competition for mates. The grey arrow represents fitness gains via alternative reproductive tactics of females that remain socially unpaired, including reproduction as single female or via parasitic egg dumping. The cost of socially pairing with a non-preferred male may e.g. result from reduced willingness to copulate leading to infertility, aggression, and reduced male brood care. Note that in empirical studies the apparent costs of pairing with a non-preferred male (cost of "dissatisfaction") and of remaining unpaired might be confounded by effects of intrinsic quality differences between the three groups of females shown in red. Also note that all choosy females (red) pay a cost of competition, which might also vary between groups, for example if some females avoid to compete.

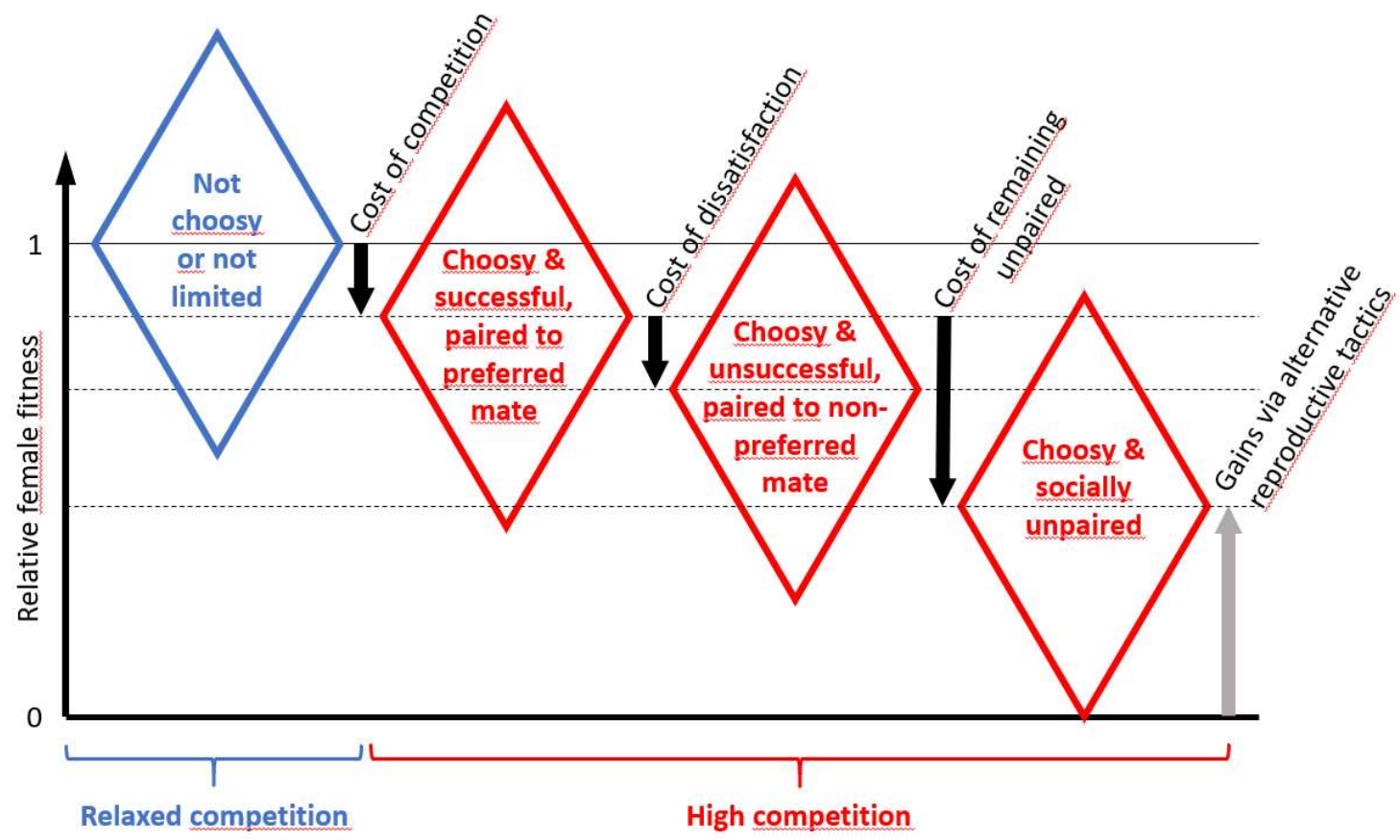


Figure 2. Relative fitness (number of independent offspring produced by each female, scaled to a mean of one within each of the 10 experimental aviaries) of the 40 females from the relaxedcompetition group ( 4 females with 8 males of their preferred natal song dialect per aviary) compared to the 80 females from the high-competition group ( 8 females with 4 males of their preferred natal song dialect per aviary). Group averages of 0.95 and 1.02 are indicated.

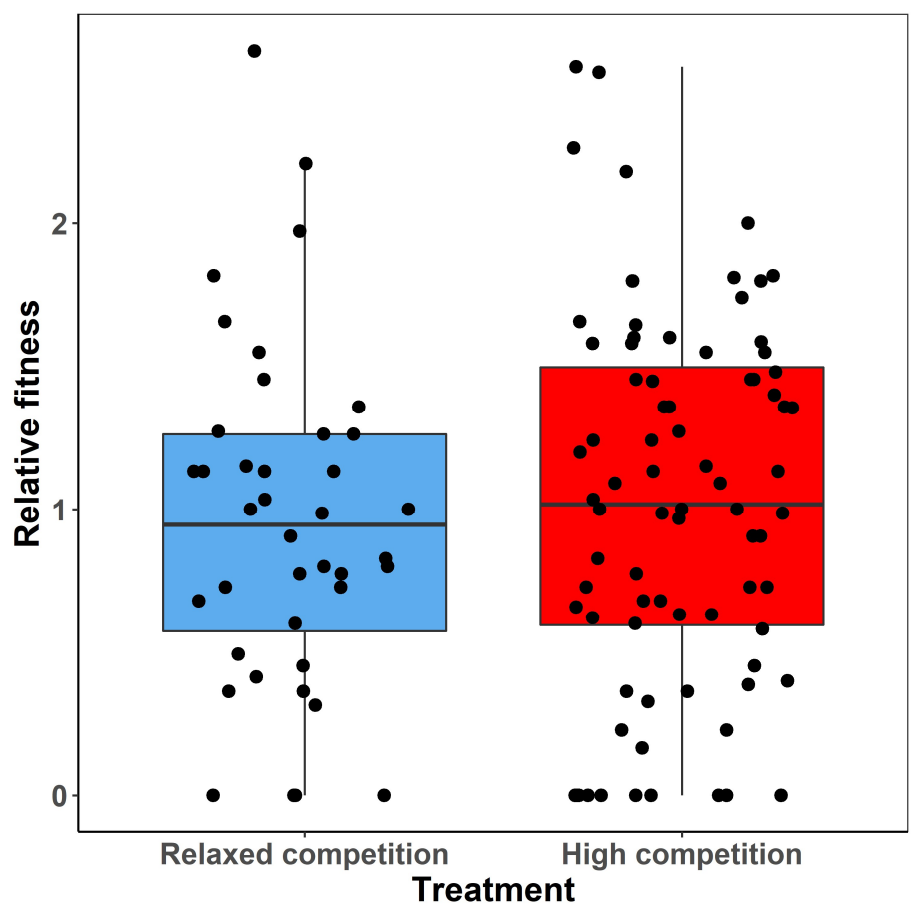


677 Figure 3. Experimental design (letters A and B stand for individuals of different song dialects in an 678 aviary; each row represents one sex) and possible pair bonds (dashes connecting letters) resulting in 679 different levels of assortative mating with regard to song dialect. Random pairing on average 680 produces $44.4 \%$ assortative pairs (pairs matched for their song dialect). "Observed parentage" refers 681 to the proportion of fertilized eggs $(N=1,074)$ of which the genetic parents were mated 682 assortatively. For comparison, four idealized scenarios of pairing are indicated together with the 683 numbers of assortative versus disassortative pairs (in parentheses).

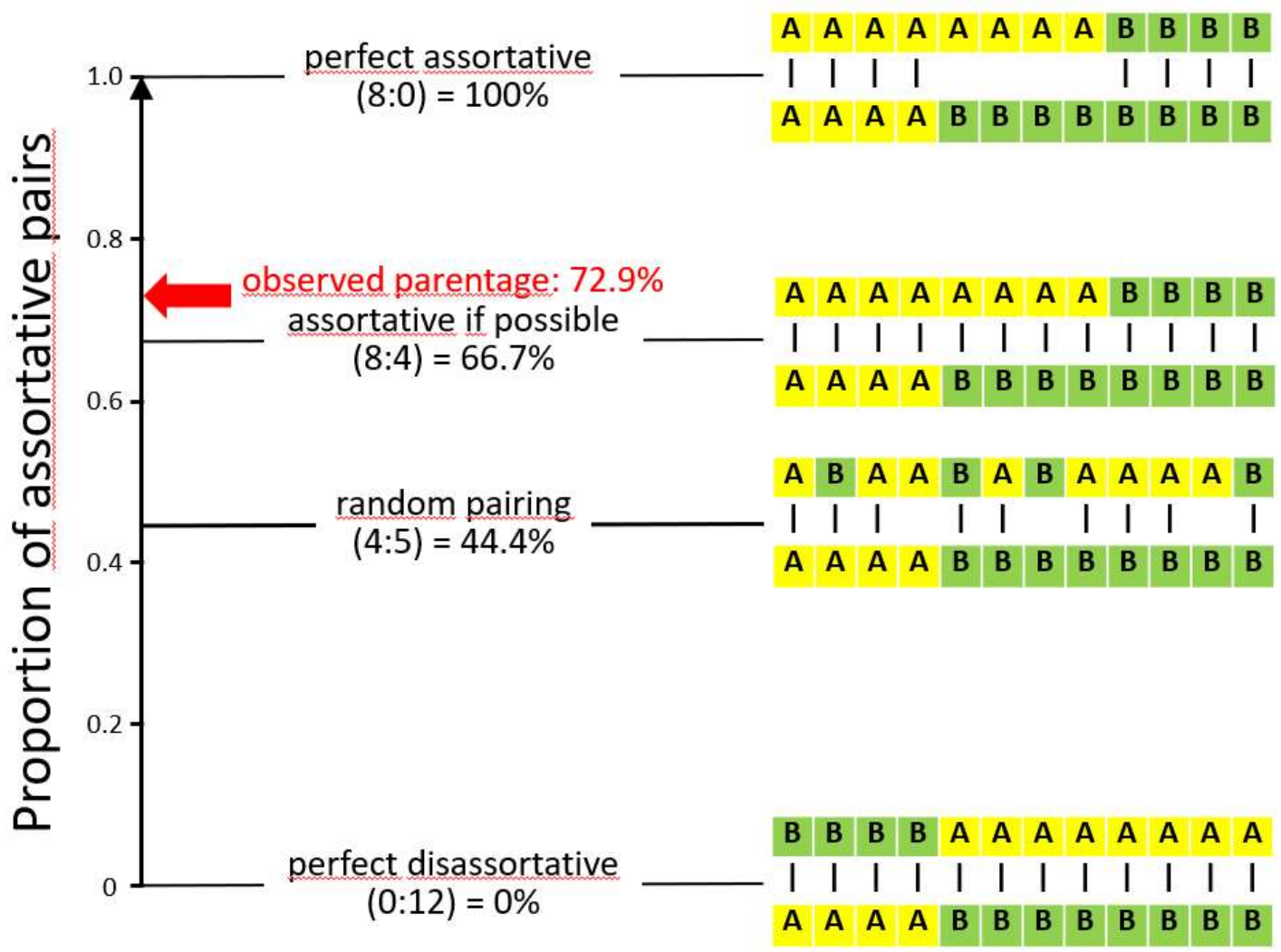

684

685 
687 Figure 4. Observed pair bonds for females from the relaxed and high-competition groups. (A, B) Pie charts showing the proportion of females in each of the two treatment groups that were either not observed as a pair (unpaired), or were seen in assortative, disassortative or both type of pair bonds (mixed). Numbers indicate the count of females in each group. (C, D) Histograms illustrating the temporal patterns of emergence of social bonds (either assortative or disassortative). Shown is the day after the start of the experiment (potentially ranging from 1 to 70 ) on which the first egg was recorded in a nest taken care of by one of the 106 breeding pairs (note that this may include parasitic eggs not laid by the focal female). The $y$-axes are scaled to compensate for the two-times larger number of females in the high-competition treatment relative to the relaxed-competition treatment. Note that assortative bonds $(\mathrm{N}=72)$ formed significantly earlier than disassortative bonds ( $\mathrm{N}=34$; back-transformed estimates 9.3 vs. 17.8 days, $\mathrm{t}$-test on log-transformed latency: $\mathrm{t}_{104}=$ $3.67, p=0.0004)$.

\section{A}

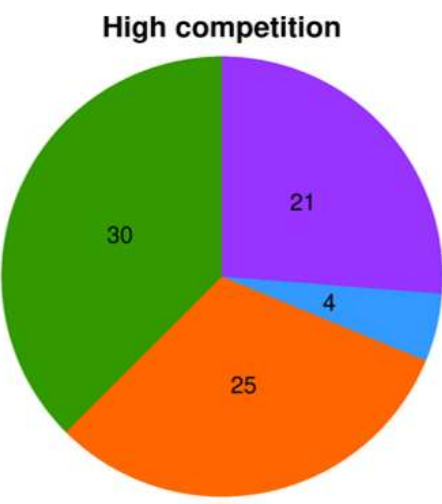

B

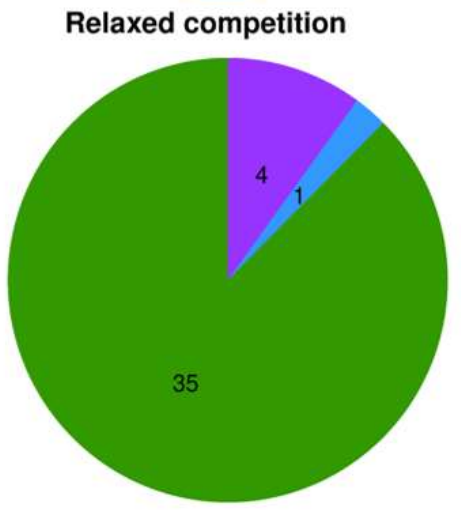

C

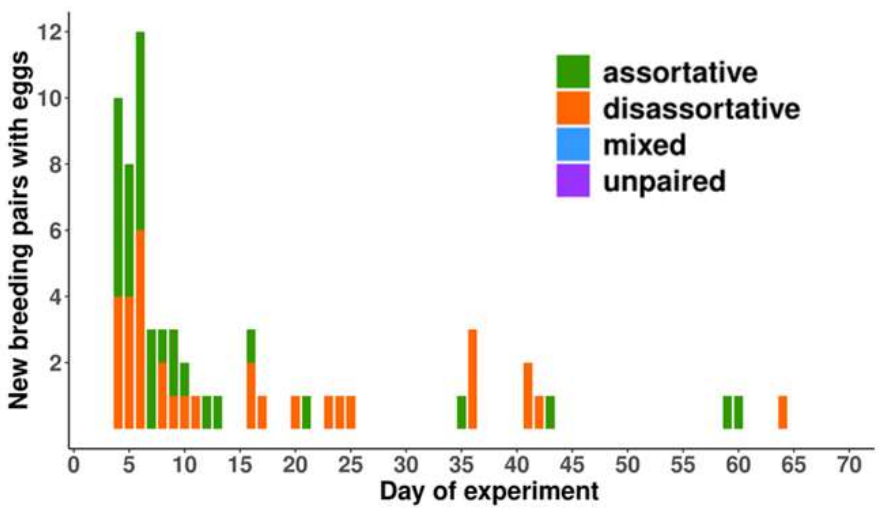

D

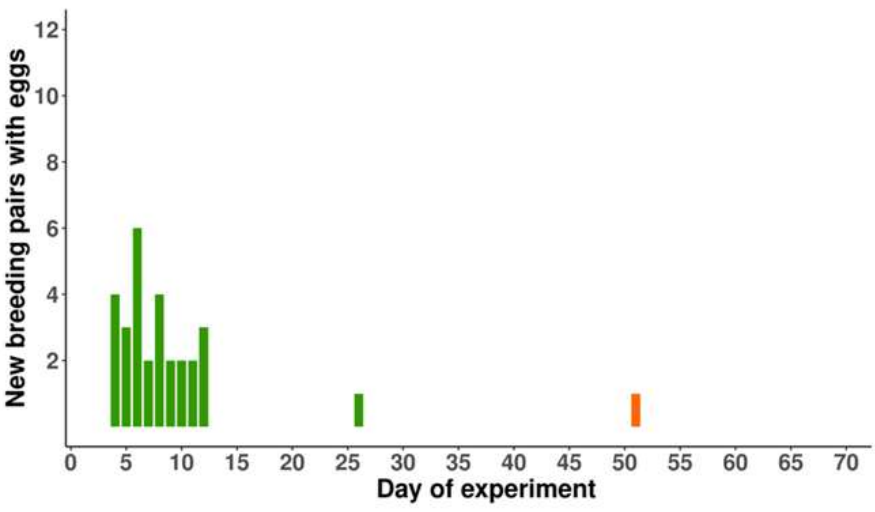

699 
Figure 5. Relative fitness ( $A$, as described in Figure 2 ) and number of "dumped eggs" laid ( $B$, wide definition of parasitic eggs, see Results) for females of different pairing status (unpaired, or mated assortatively, disassortatively or both, as in Figure 4A, B) in each of the two treatment groups (relaxed competition versus high competition). Horizontal lines indicate group averages.

\section{A}

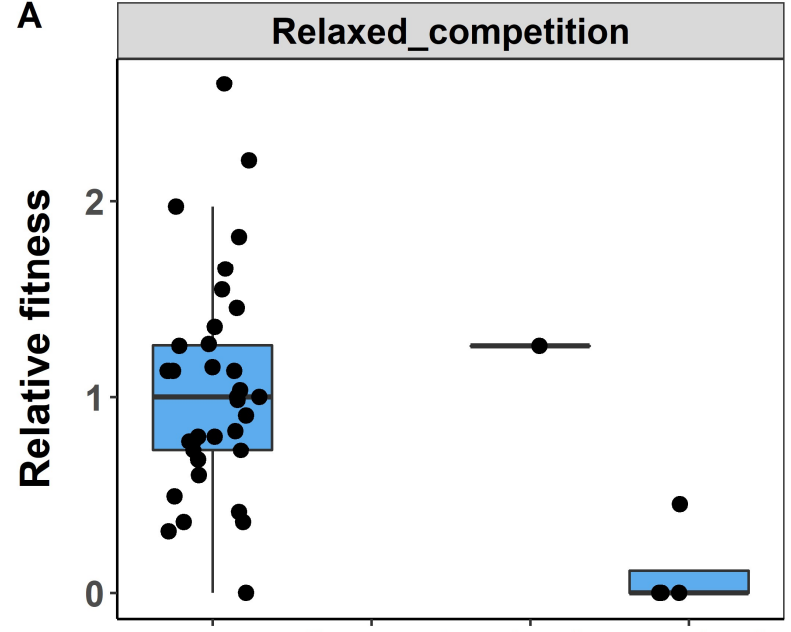

assort disassort mixed unpaired

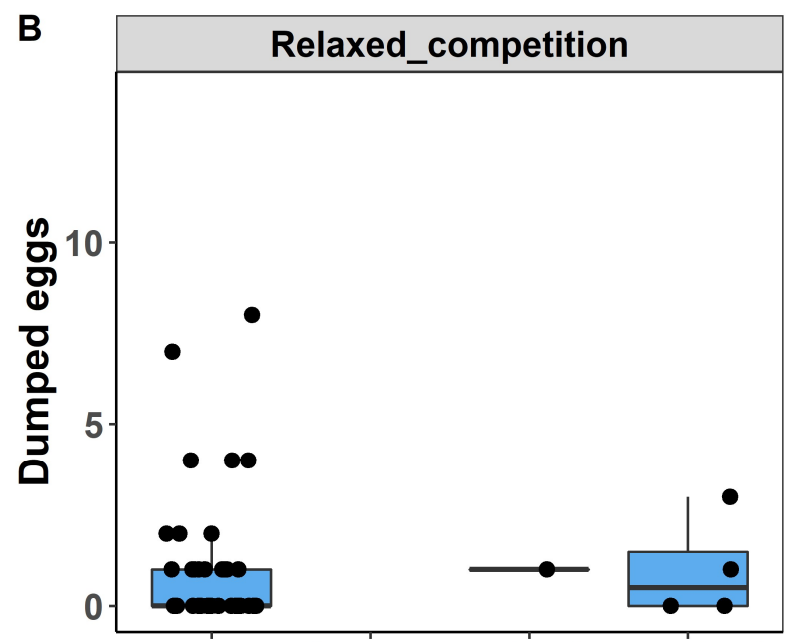

assort disassort mixed unpaired

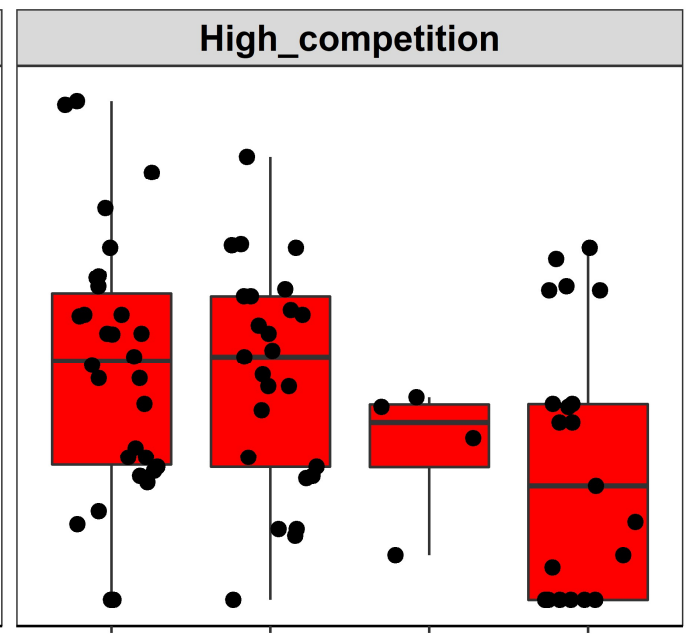

assort disassort mixed unpaired

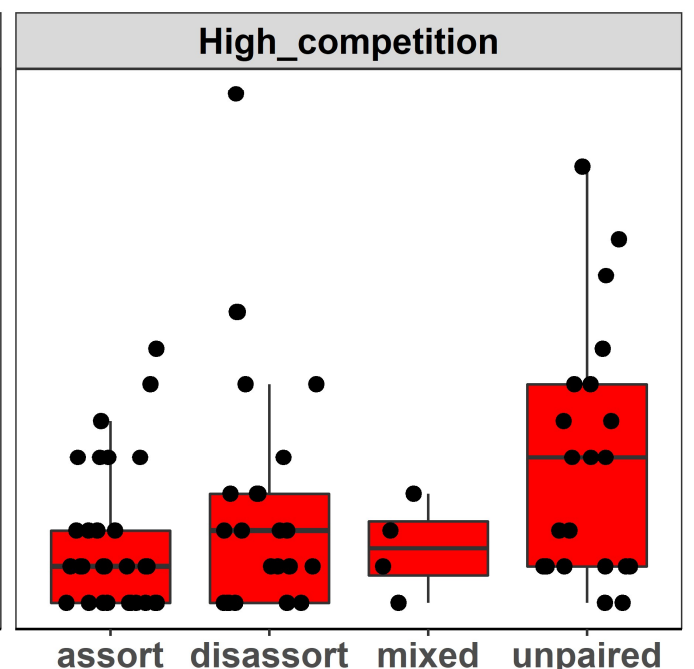

705 
708 Figure 6. Proportion of eggs sired outside the monogamous pair bond (extra-pair paternity, EPP, 709 grey bars) versus within-pair paternity (WPP, white bars) for three groups of females with a single 710 social pair bond. These are (1) assortatively paired females $(n=35)$ from the relaxed competition 711 treatment (blue), (2) assortatively paired females ( $n=28$, one of which did not lay any eggs) from 712 the high competition treatment (red), and disassortatively paired females $(n=21)$ from the high 713 competition treatment. For each category of eggs, we indicate the proportion that is sired 714 assortatively ('assort') for song dialect and in parentheses the random expectations ('exp') for this 715 proportion of assortative mating based on the number of available extra-pair males of each song 716 dialect. For more details see also S16 Table.

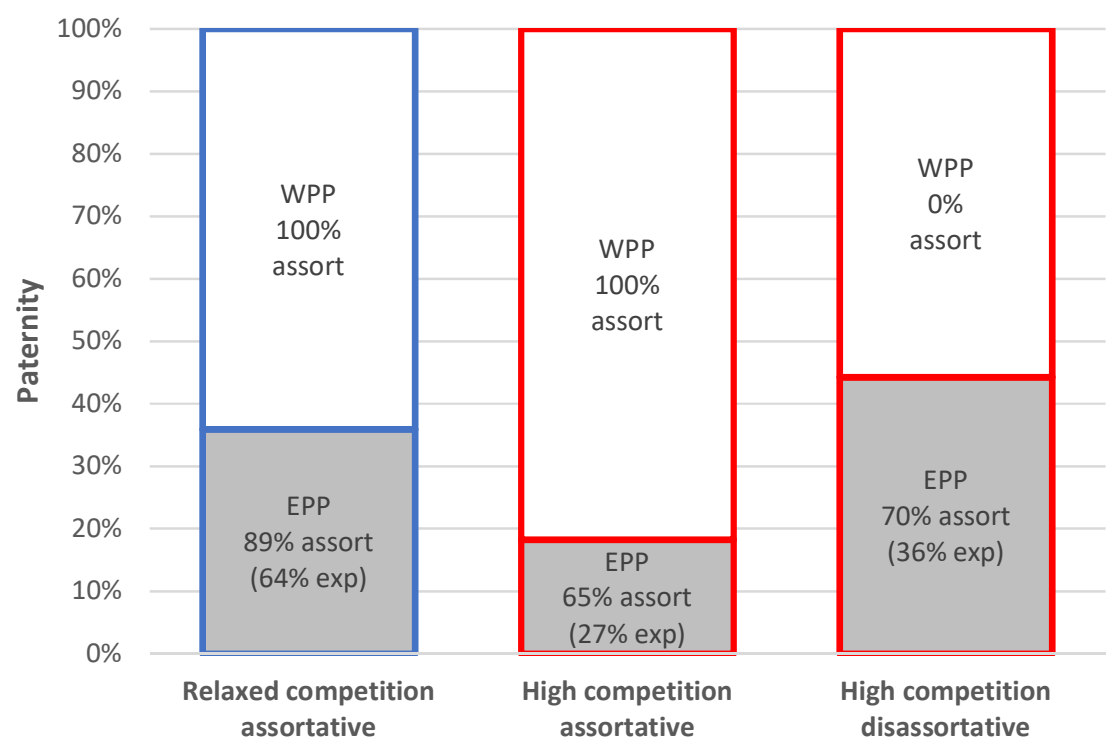




\section{Supporting Information}

719 S1 Table. Female relative fitness as a function of treatment and confounding factors.

\begin{tabular}{|c|c|c|c|c|}
\hline Model 1 & Estimate & $\mathrm{SE}$ & $t$ & $p$ \\
\hline \multicolumn{5}{|l|}{ Model 1a } \\
\hline Intercept & 0.955 & 0.097 & & \\
\hline Treatment (high competition) & 0.067 & 0.119 & 0.57 & 0.57 \\
\hline Inbreeding coefficient (scaled) & -3.143 & 1.126 & -2.79 & 0.006 \\
\hline \multicolumn{5}{|l|}{ Model 1b } \\
\hline Intercept & 0.914 & 0.102 & & \\
\hline Treatment (high competition) & 0.128 & 0.128 & 1.01 & 0.32 \\
\hline Inbreeding coefficient (scaled) & -3.535 & 1.256 & -2.82 & 0.006 \\
\hline Number of peers in natal aviary (scaled) & -0.017 & 0.012 & -1.46 & 0.15 \\
\hline Relative fitness of mother (scaled) & 0.034 & 0.020 & 1.66 & 0.099 \\
\hline
\end{tabular}

720

721 S2 Table. Number of genetically verified eggs laid per female as a function of treatment and female 722 inbreeding coefficient (mixed-effect model 2).

\begin{tabular}{|c|c|c|c|c|c|c|}
\hline Model 2 & Levels & Estimate & SE & $\mathrm{df}$ & $t$ & $p$ \\
\hline \multicolumn{7}{|l|}{ Random effects (variance) } \\
\hline Natal aviary & 15 & 0.16 & & & & \\
\hline Experimental aviary & 10 & 0.22 & & & & \\
\hline Residual & 120 & 12.46 & & & & \\
\hline \multicolumn{7}{|l|}{ Fixed effects } \\
\hline Intercept & & 8.56 & 0.59 & 34.8 & & \\
\hline Treatment (high competition) & & 0.64 & 0.70 & 20.1 & 0.91 & 0.37 \\
\hline Inbreeding coefficient (scaled) & & -18.83 & 6.73 & 79.1 & -2.80 & 0.0065 \\
\hline
\end{tabular}

S3 Table. Latency (in days, log10-transformed) to lay the first genetically verified egg as a function of 725 treatment and female inbreeding coefficient.

\begin{tabular}{|c|c|c|c|c|c|c|}
\hline Model 3 & Levels & Estimate & $\mathrm{SE}$ & $\mathrm{df}$ & $t$ & $p$ \\
\hline \multicolumn{7}{|l|}{ Random effects (variance) } \\
\hline Natal aviary & 15 & 0.0061 & & & & \\
\hline Experimental aviary & 10 & 0 & & & & \\
\hline Residual & 120 & 0.1012 & & & & \\
\hline \multicolumn{7}{|l|}{ Fixed effects } \\
\hline Intercept & & 0.92 & 0.057 & 37.5 & & \\
\hline Treatment (high competition) & & -0.033 & 0.069 & 45.8 & -0.48 & 0.63 \\
\hline Inbreeding coefficient (scaled) & & 1.07 & 0.623 & 95.1 & 1.72 & 0.09 \\
\hline
\end{tabular}


727 S4 Table. Probability of remaining socially unpaired (not recorded participating in one of 106 nest-attending 728 pairs) as a function of treatment and female inbreeding coefficient (binomial model on $n=120$ females).

\begin{tabular}{lccccc}
\hline Model 4 & Levels & Estimate & SE & $z$ & $p$ \\
\hline Random effects (variance) & 15 & 0.04 & & & \\
$\quad$ Natal aviary & 10 & 0.32 & & & \\
$\quad$ Experimental aviary & & & & & \\
& & -2.63 & 0.66 & & \\
Fixed effects & 1.49 & 0.71 & 2.11 & 0.035 \\
$\quad$ Intercept & 20.4 & 7.00 & 2.91 & 0.0036 \\
$\quad$ Treatment (high competition) & & & & & \\
$\quad$ Inbreeding coefficient (scaled) & & & & & \\
&
\end{tabular}

729

S5 Table. Number of social pair bonds observed per female (range 0-2) as a function of treatment and female inbreeding coefficient (Gaussian mixed-effect model).

\begin{tabular}{|c|c|c|c|c|c|c|}
\hline Model 5 & Levels & Estimate & SE & df & $t$ & $p$ \\
\hline \multicolumn{7}{|l|}{ Random effects (variance) } \\
\hline Natal aviary & 15 & 0.015 & & & & \\
\hline Experimental aviary & 10 & 0.007 & & & & \\
\hline Residual & 120 & 0.248 & & & & \\
\hline \multicolumn{7}{|l|}{ Fixed effects } \\
\hline Intercept & & 0.931 & 0.092 & 30.8 & & \\
\hline Treatment (high competition) & & -0.088 & 0.108 & 28.8 & -0.82 & 0.42 \\
\hline Inbreeding coefficient (scaled) & & -3.18 & 0.995 & 96.7 & -3.20 & 0.0019 \\
\hline
\end{tabular}

732

733 S6 Table. Number of assortative social pair bonds observed per female (range 0-2) as a function of treatment 734 and female inbreeding coefficient (Gaussian mixed-effect model).

\begin{tabular}{|c|c|c|c|c|c|c|}
\hline Model 6 & Levels & Estimate & SE & df & $t$ & $p$ \\
\hline \multicolumn{7}{|l|}{ Random effects (variance) } \\
\hline Natal aviary & 15 & 0 & & & & \\
\hline Experimental aviary & 10 & 0 & & & & \\
\hline Residual & 120 & 0.221 & & & & \\
\hline \multicolumn{7}{|l|}{ Fixed effects } \\
\hline Intercept & & 0.90 & 0.074 & 117 & & \\
\hline Treatment (high competition) & & -0.45 & 0.091 & 117 & -4.96 & $<0.0001$ \\
\hline Inbreeding coefficient (scaled) & & -2.26 & 0.863 & 117 & -2.62 & 0.0099 \\
\hline
\end{tabular}


736 S7 Table. Number of disassortative social pair bonds observed per female (range $0-2$ ) as a function of 737 treatment and female inbreeding coefficient (Gaussian mixed-effect model).

\begin{tabular}{|c|c|c|c|c|c|c|}
\hline Model 7 & Levels & Estimate & $\mathrm{SE}$ & df & $t$ & $p$ \\
\hline \multicolumn{7}{|l|}{ Random effects (variance) } \\
\hline Natal aviary & 15 & 0.011 & & & & \\
\hline Experimental aviary & 10 & 0.011 & & & & \\
\hline Residual & 120 & 0.221 & & & & \\
\hline \multicolumn{7}{|l|}{ Fixed effects } \\
\hline Intercept & & 0.035 & 0.088 & 29.2 & & \\
\hline Treatment (high competition) & & 0.365 & 0.100 & 21.8 & 3.65 & 0.0014 \\
\hline Inbreeding coefficient (scaled) & & -0.824 & 0.944 & 97.6 & -0.87 & 0.38 \\
\hline
\end{tabular}

738

739 S8 Table. Latency (in days, log10-transformed) to the first recorded egg in a clutch attended as one of the 740106 social pairs as a function of treatment and female inbreeding coefficient.

\begin{tabular}{|c|c|c|c|c|c|c|}
\hline Model 8 & Levels & Estimate & SE & df & $t$ & $p$ \\
\hline \multicolumn{7}{|l|}{ Random effects (variance) } \\
\hline Natal aviary & 15 & 0 & & & & \\
\hline Experimental aviary & 10 & 0.006 & & & & \\
\hline Residual & 120 & 0.200 & & & & \\
\hline \multicolumn{7}{|l|}{ Fixed effects } \\
\hline Intercept & & 0.897 & 0.075 & 38.2 & & \\
\hline Treatment (high competition) & & 0.234 & 0.087 & 105.9 & 2.70 & 0.008 \\
\hline Inbreeding coefficient (scaled) & & 3.650 & 0.852 & 88.6 & 4.28 & 0.00005 \\
\hline
\end{tabular}

S9 Table. Number of clutches attended as a single mother (range $\mathbf{0 - 2}$ ) as a function of treatment and female 743 inbreeding coefficient (Gaussian mixed-effect model).

\begin{tabular}{|c|c|c|c|c|c|c|}
\hline Model 9 & Levels & Estimate & $\mathrm{SE}$ & $\mathrm{df}$ & $t$ & $p$ \\
\hline \multicolumn{7}{|l|}{ Random effects (variance) } \\
\hline Natal aviary & 15 & 0.009 & & & & \\
\hline Experimental aviary & 10 & 0 & & & & \\
\hline Residual & 120 & 0.155 & & & & \\
\hline \multicolumn{7}{|l|}{ Fixed effects } \\
\hline Intercept & & 0.127 & 0.070 & 33.3 & & \\
\hline Treatment (high competition) & & 0.049 & 0.085 & 40.8 & 0.58 & 0.57 \\
\hline Inbreeding coefficient (scaled) & & 1.092 & 0.768 & 90.7 & 1.42 & 0.16 \\
\hline
\end{tabular}


S10 Table. Number of eggs which the female took care of (recorded as a social mother in any pairing constellation) as a function of treatment and female inbreeding coefficient.

\begin{tabular}{|c|c|c|c|c|c|c|}
\hline Model 10 & Levels & Estimate & $\mathrm{SE}$ & df & $t$ & $p$ \\
\hline \multicolumn{7}{|l|}{ Random effects (variance) } \\
\hline Natal aviary & 15 & 0 & & & & \\
\hline Experimental aviary & 10 & 1.13 & & & & \\
\hline Residual & 120 & 10.14 & & & & \\
\hline \multicolumn{7}{|l|}{ Fixed effects } \\
\hline Intercept & & 7.41 & 0.61 & 28.7 & & \\
\hline Treatment (high competition) & & -0.78 & 0.62 & 108.1 & -1.27 & 0.21 \\
\hline Inbreeding coefficient (scaled) & & -23.65 & 6.34 & 111.7 & -3.73 & 0.0003 \\
\hline
\end{tabular}

747

748 S11 Table. Number of genetically verified eggs by a female that were cared for by another female as a

749 function of treatment and female inbreeding coefficient (mixed-effect model 2 ).

\begin{tabular}{|c|c|c|c|c|c|c|}
\hline Model 11 & Levels & Estimate & $\mathrm{SE}$ & df & $t$ & $p$ \\
\hline \multicolumn{7}{|l|}{ Random effects (variance) } \\
\hline Natal aviary & 15 & 0 & & & & \\
\hline Experimental aviary & 10 & 0 & & & & \\
\hline Residual & 120 & 4.15 & & & & \\
\hline \multicolumn{7}{|l|}{ Fixed effects } \\
\hline Intercept & & 0.80 & 0.32 & 117 & & \\
\hline Treatment (high competition) & & 0.83 & 0.39 & 117 & 2.10 & 0.038 \\
\hline Inbreeding coefficient (scaled) & & 2.70 & 3.74 & 117 & 0.72 & 0.47 \\
\hline
\end{tabular}

750

751 S12 Table. Number of genetically verified eggs per female that she did not take care of as a function of 752 treatment and female inbreeding coefficient (mixed-effect model 2).

\begin{tabular}{|c|c|c|c|c|c|c|}
\hline Model 12 & Levels & Estimate & $\mathrm{SE}$ & $\mathrm{df}$ & $t$ & $p$ \\
\hline \multicolumn{7}{|l|}{ Random effects (variance) } \\
\hline Natal aviary & 15 & 0.23 & & & & \\
\hline Experimental aviary & 10 & 0 & & & & \\
\hline Residual & 120 & 6.92 & & & & \\
\hline \multicolumn{7}{|l|}{ Fixed effects } \\
\hline Intercept & & 1.11 & 0.45 & 39.0 & & \\
\hline Treatment (high competition) & & 1.48 & 0.55 & 44.0 & 2.72 & 0.0094 \\
\hline Inbreeding coefficient (scaled) & & 3.51 & 5.03 & 86.5 & 0.70 & 0.49 \\
\hline
\end{tabular}


754 S13 Table. Relative counts of eggs that the female dumped (in a strict sense) versus her remaining eggs as a 755 function of treatment and female inbreeding coefficient (binomial mixed-effect model).

\begin{tabular}{lccccc}
\hline Model 13 & Levels & Estimate & SE & $z$ & $p$ \\
\hline Random effects (variance) & 120 & 1.97 & & & \\
$\quad$ Female identity & 15 & 0 & & & \\
Natal aviary & 10 & 0 & & & \\
Experimental aviary & & & & & \\
& & -2.96 & 0.35 & & \\
Fixed effects & & 0.87 & 0.39 & 2.21 & 0.027 \\
$\quad$ Intercept & & 6.76 & 3.75 & 1.80 & 0.071 \\
Treatment (high competition) & & & & \\
Inbreeding coefficient (scaled) & & & & & \\
\end{tabular}

756

757 S14 Table. Relative counts of eggs that the female dumped (in a wide sense) versus took care of as a

758 function of treatment and female inbreeding coefficient (binomial mixed-effect model).

\begin{tabular}{lccccc}
\hline Model 14 & Levels & Estimate & SE & $z$ & $p$ \\
\hline Random effects (variance) & 120 & 1.54 & & & \\
$\quad$ Female identity & 15 & 0 & & & \\
Natal aviary & 10 & 0 & & & \\
Experimental aviary & & & & & \\
& & -2.66 & 0.36 & & \\
Fixed effects & & 1.36 & 0.41 & 3.33 & 0.0009 \\
$\quad$ Intercept & & 12.45 & 4.04 & 3.09 & 0.002 \\
Treatment (high competition) & & & & \\
Inbreeding coefficient (scaled) & & & & & \\
\end{tabular}

759

760

761

762

S15 Table. Relative counts of eggs that developed into independent young and her remaining eggs that did not reach independence as a function of treatment and female inbreeding coefficient (binomial mixed-effect model).

\begin{tabular}{lccccc}
\hline Model 15 & Levels & Estimate & SE & $z$ & $p$ \\
\hline Random effects (variance) & 120 & 0.78 & & & \\
$\quad$ Female identity & 15 & 0 & & & \\
$\quad$ Natal aviary & 10 & 0.08 & & & \\
$\quad$ Experimental aviary & & & & & \\
& & 0.064 & 0.21 & & \\
Fixed effects & & -0.036 & 0.23 & -0.16 & 0.87 \\
$\quad$ Intercept & & -6.51 & 2.85 & -2.29 & 0.022 \\
$\quad$ Treatment (high competition) & & & & \\
$\quad$ Inbreeding coefficient (scaled) & & & & & \\
\end{tabular}


764 S16 Table. Descriptive statistics on extrapair mating by three groups of females (dependent on competition 765 treatment and social pairing status).

\begin{tabular}{|c|c|c|c|}
\hline Dependent variable & $\begin{array}{c}\text { Low } \\
\text { competition } \\
\text { paired } \\
\text { assortatively }\end{array}$ & $\begin{array}{c}\text { High } \\
\text { competition } \\
\text { paired } \\
\text { assortatively }\end{array}$ & $\begin{array}{c}\text { High } \\
\text { competition } \\
\text { paired } \\
\text { disassortatively }\end{array}$ \\
\hline$\%$ females with EPP ( $\mathrm{N}$ with EPP / $\mathrm{N}$ total females) & $66(23 / 35)$ & $44(12 / 27)$ & $81(17 / 21)$ \\
\hline$\% \mathrm{EPP}$ (of eggs) in females with $\mathrm{EPP} \pm \mathrm{SE}$ & $55 \pm 7$ & $41 \pm 8$ & $62 \pm 9$ \\
\hline$\%$ EPP of all eggs (N EPP / $N$ total eggs) & $36(112 / 312)$ & $18(46 / 252)$ & $44(81 / 183)$ \\
\hline$\%$ assortative of EP-eggs ( $\mathrm{N}$ assortative / N EPP) & $89(100 / 112)$ & $65(30 / 46)$ & $70(57 / 81)$ \\
\hline $\begin{array}{l}\% \text { assortative of EP-relationships ( } \mathrm{N} \text { assortative / } \mathrm{N} \\
\text { total EP-relationships) }\end{array}$ & $87(40 / 46)$ & $53(9 / 17)$ & $59(19 / 32)$ \\
\hline $\begin{array}{l}\% \text { assortative expected of EP-relationships ( } \mathrm{N} \\
\text { assortative / } \mathrm{N} \text { total EP-males in aviary) }\end{array}$ & $64(7 / 11)$ & $27(3 / 11)$ & $36(4 / 11)$ \\
\hline $\begin{array}{l}\mathrm{N} \text { eggs sired by assortative EP-male per } \\
\text { relationship } \pm \mathrm{SE} \text { ( } \mathrm{N} \text { relationships) }\end{array}$ & $2.5 \pm 0.3(40)$ & $3.3 \pm 0.6(9)$ & $3.0 \pm 0.5(19)$ \\
\hline $\begin{array}{l}\mathrm{N} \text { eggs sired by disassortative EP-male per } \\
\text { relationship } \pm \text { SE ( } N \text { relationships })\end{array}$ & $2.0 \pm 0.4(6)$ & $2.0 \pm 0.3(8)$ & $1.8 \pm 0.3(13)$ \\
\hline
\end{tabular}




\section{S1 Text}

R-code and model outputs of planned models 1-3 and post-hoc models 4-15.

\section{Explanation of variables:}

Dependent variables:

relfit $=$ relative fitness, scaled to a mean of one $(12 \mathrm{x}$ number of independent young / total number of independent young in the experimental aviary)

Neggsvalid = Count of genetically verified eggs produced by a female (total sum $=1,080$ eggs)

loglatencygen $=\log 10$-transformed latency in days to lay the first genetically verified egg

unpaired $=$ not participating in any of the 106 heterosexual pair bonds $(0=$ no, $1=$ yes)

Nsocbonds = number of social pair bonds observed per female (range $0-2$, total sum $=106$ )

N_assort_bonds = number of assortative social pair bonds observed per female (range $0-2$, total sum $=72$ )

$\mathrm{N}$ _disassort_bonds $=$ number of disassortative social pair bonds observed per female (range $0-2$, total sum = 34)

loglatencysoc $=\log 10$-transformed latency in days to the first recorded egg in a clutch attended as one of the 106 social pairs

Singlemomclutches $=$ number of clutches attended as a single mother (range $0-2$, total sum $=18$ )

Eggsselfcaredfor $=$ number of eggs for which the female was recorded to attend as a social mother in whatever pairing constellation

Eggsdumpedstrict $=$ number of genetically verified eggs of a female that were cared for by another female Eggsdumpedwide $=$ number of genetically verified eggs of a female that she did not care for herself (equal to Neggsvalid - Eggsselfcaredfor)

Propdumpedstrict $=$ Relative counts of eggs that a female dumped in the strict sense and her remaining eggs Propdumpedwide $=$ Relative counts of eggs that a female dumped in the wide sense and her remaining eggs Propeggsuccess $=$ Relative counts of eggs of a female that developed into independent young and her remaining eggs that did not reach independence

Fixed effects:

trt $=$ female treatment $(1=$ relaxed competition, 2 = high competition)

Fped $=$ pedigree-based inbreeding coefficient $\mathrm{F}$ of the female

Npeers = number of peers reaching independence within the female's natal aviary

motherfitness $=$ number of independent offspring produced by the mother in the previous year within an equally-long time window

Random effects:

ExpAV $=$ experimental aviary (10 levels)

NatalAV = natal aviary (16 levels)

Ind_ID = female identity (120 levels)

Code :

require(Ime4)

library("ImerTest")

dd<-read.csv("./choosiness1_females.csv",header=T) dd\$NatalAV<-factor(dd\$NatalAV)

dd\$ExpAV<-factor(dd\$ExpAV)

dd\$trt<-factor(dd\$trt) 
818

819

820

821

822

823

824

825

826

827

828

829

830

831

832

833

834

835

836

837

838

839

840

841

842

843

844

845

846

847

848

849

850

851

852

853

854

855

856

857

858

859

860

861

862

863

864

865

866

867

868

869

870

871

872

873

874

875

876

877

878

\section{Model 1a}

$\mathrm{m} 1 \mathrm{a}<-\mathrm{glm}($ relfit $\sim \operatorname{trt}+\mathrm{scale}($ Fped,scale=F), data=dd); $\operatorname{summary}(\mathrm{m} 1 \mathrm{a})$

Coefficients:

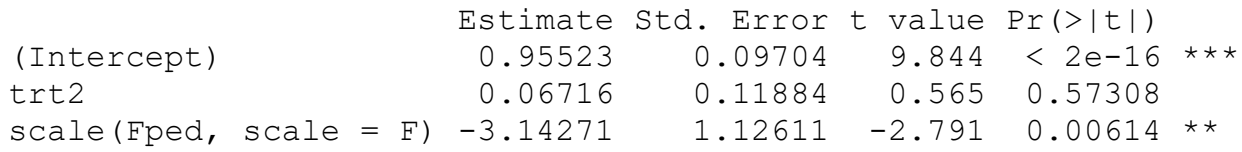

m1aestimates<-glm(relfit $\sim$-1+trt+scale(Fped,scale=F), data=dd); summary(m1aestimates)

Coefficients:

$\begin{array}{lrrrr} & \text { Estimate Std. Error t value } & \text { Pr }(>|t|) \\ \text { trt1 } & 0.95523 & 0.09704 & 9.844 & <2 e-16 \star \star \star \\ \text { trt2 } & 1.02239 & 0.06861 & 14.901 & <2 e-16 \star \star \star \\ \text { scale(Fped, scale }=F) & -3.14271 & 1.12611 & -2.791 & 0.00614 * \star\end{array}$

Model 1b

$\mathrm{m} 1 \mathrm{~b}<-$ glm(relfit trt+scale(Fped,scale=F)+scale(Npeers,scale=F)+scale(motherfitness,scale=F), data=dd); summary(m1b)

Coefficients:

(Intercept)

trt2

scale (Fped, scale $=$ F)

$\begin{array}{rr}\text { Estimate } & \text { Std. Error } \\ 0.91436 & 0.10175\end{array}$

$t$ value $\operatorname{Pr}(>|t|)$

scale (Npeers, scale $=F$ )

0.12846

0.12779

$8.9875 .94 e-15$

$-3.53541$

1.25551

$-0.01711$

scale(motherfitness, scale $=F$ )

0.03406

0.01174

$1.005 \quad 0.31691$

-2.8160 .00573 **

$\begin{array}{ll}-1.457 & 0.14777\end{array}$

Model 2

require(Ime4)

m2<-Imer(Neggsvalid trt+scale(Fped,scale=F)+(1|ExpAV)+(1| NatalAV), data=dd); summary (m2)

Random effects:

Groups Name Variance Std.Dev.

$\begin{array}{lll}\text { NatalAV (Intercept) } & 0.1557 & 0.3945\end{array}$

$\begin{array}{llll}\text { ExpAV (Intercept) } & 0.2179 & 0.4668\end{array}$

Residual $\quad 12.4647 \quad 3.5305$

Number of obs: 120, groups: NatalAV, 15; ExpAV, 10

Fixed effects:

$\begin{array}{lrrrrr} & \text { Estimate Std. Error } & \text { df } & t \text { value } \operatorname{Pr}(>|t|) \\ \text { (Intercept) } & 8.5633 & 0.5931 & 34.7822 & 14.439 & 2.94 e-16 * * * \\ \text { trt2 } & 0.6400 & 0.7032 & 20.1072 & 0.910 & 0.37351 \\ \text { scale(Eped, scale }=\text { F) } & -18.8353 & 6.7343 & 79.0559 & -2.797 & 0.00648 * *\end{array}$

Model 3

m3<-Imer(loglatencygen $\sim$ trt+scale(Fped,scale=F)+(1|ExpAV)+(1|NatalAV), data=dd); summary(m3)

Random effects:

Groups Name Variance Std.Dev.

NatalAV (Intercept) 0.0061070 .07815

ExpAV (Intercept) $0.000000 \quad 0.00000$

Residual 0.1012160 .31814

Number of obs: 120, groups: NatalAV, 15; ExpAV, 10

Fixed effects: 


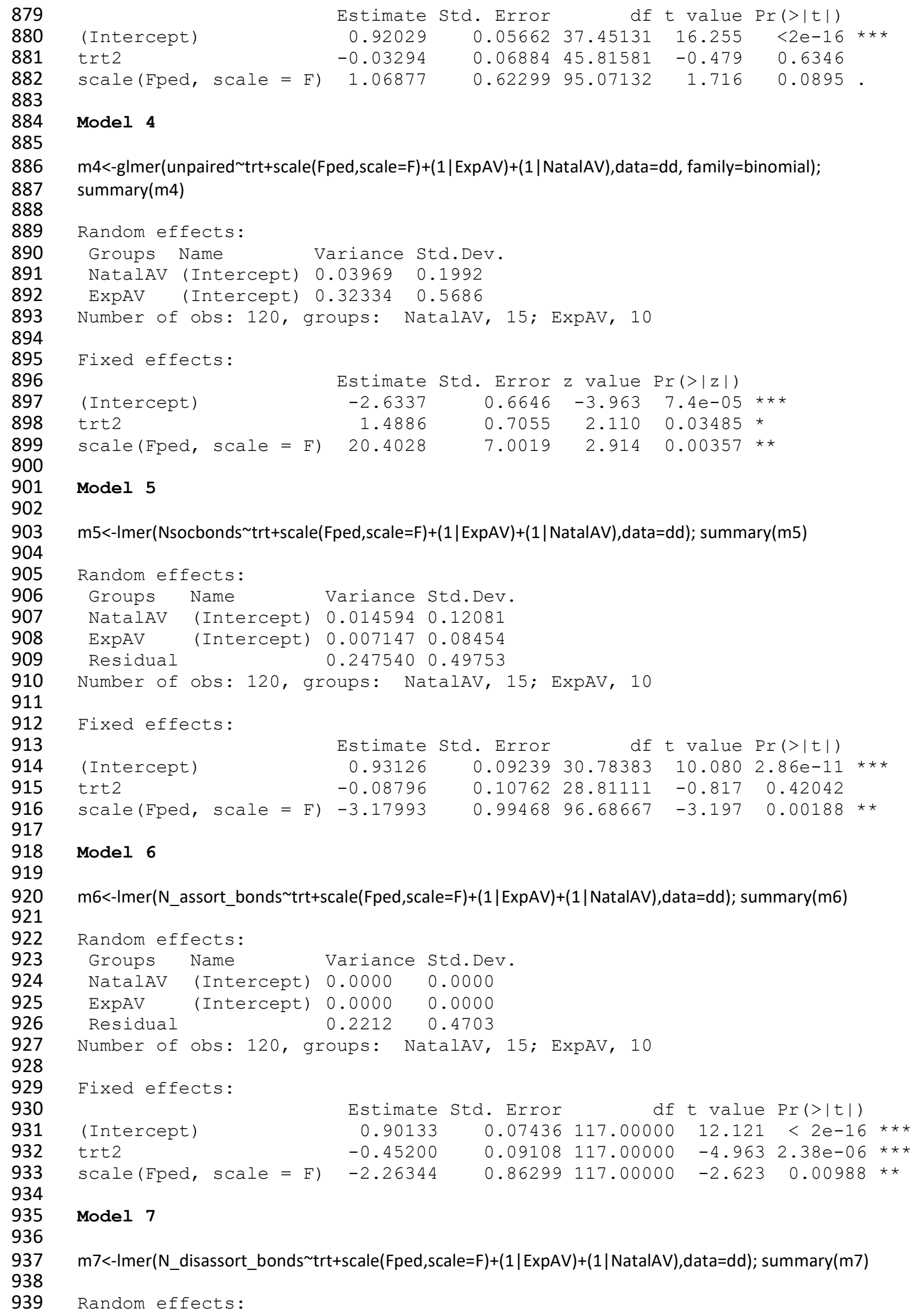

\section{Model 4}

m4<-glmer(unpaired $\sim$ trt+scale(Fped,scale=F)+(1|ExpAV)+(1|NatalAV), data=dd, family=binomial); summary $(\mathrm{m} 4)$ 
bioRxiv preprint doi: https://doi.org/10.1101/2021.05.04.442574; this version posted May 4, 2021. The copyright holder for this preprint (which

was not certified by peer review) is the author/funder, who has granted bioRxiv a license to display the preprint in perpetuity. It is made available under aCC-BY 4.0 International license.

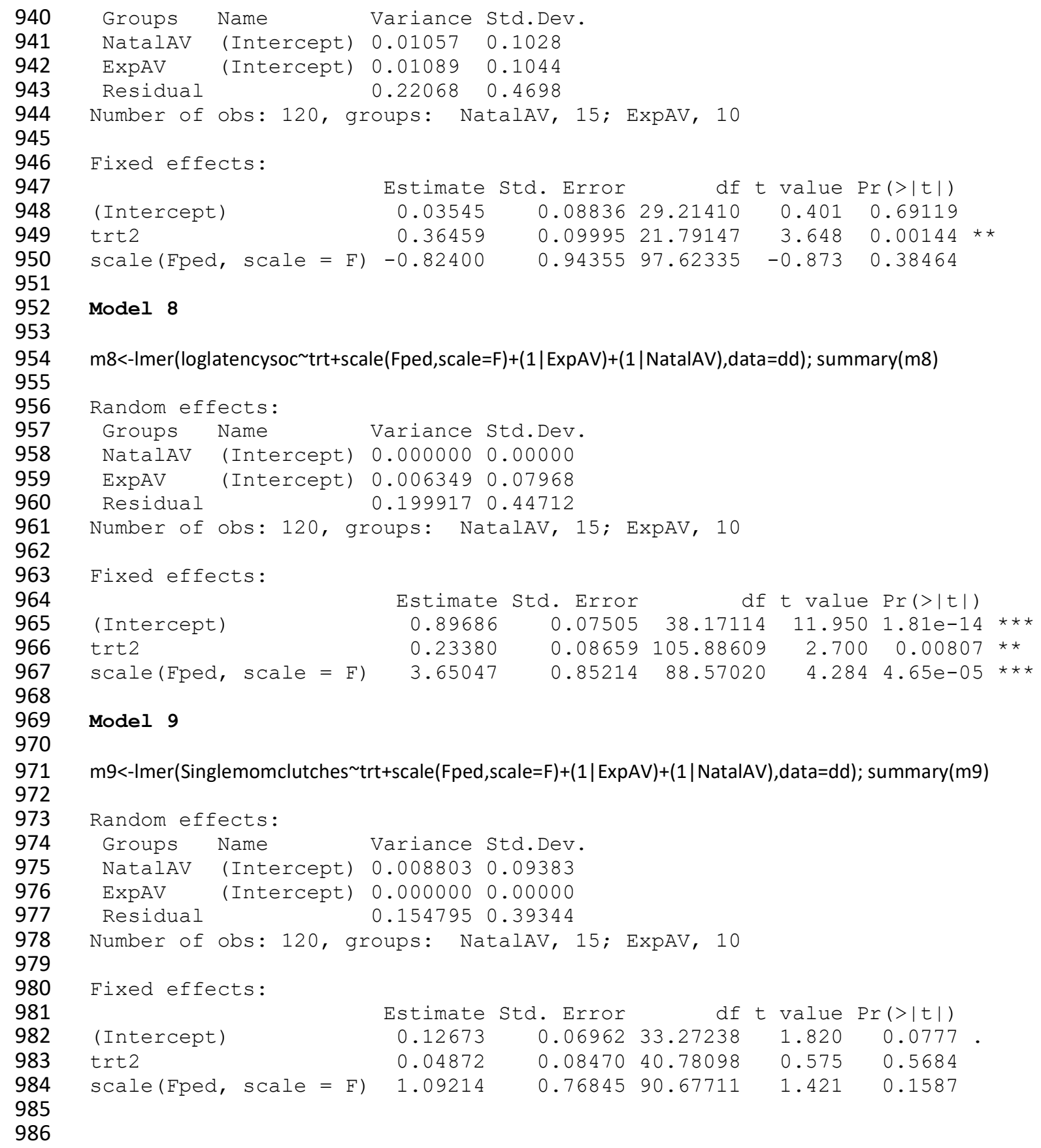


bioRxiv preprint doi: https://doi.org/10.1101/2021.05.04.442574; this version posted May 4, 2021. The copyright holder for this preprint (which

was not certified by peer review) is the author/funder, who has granted bioRxiv a license to display the preprint in perpetuity. It is made available under aCC-BY 4.0 International license.

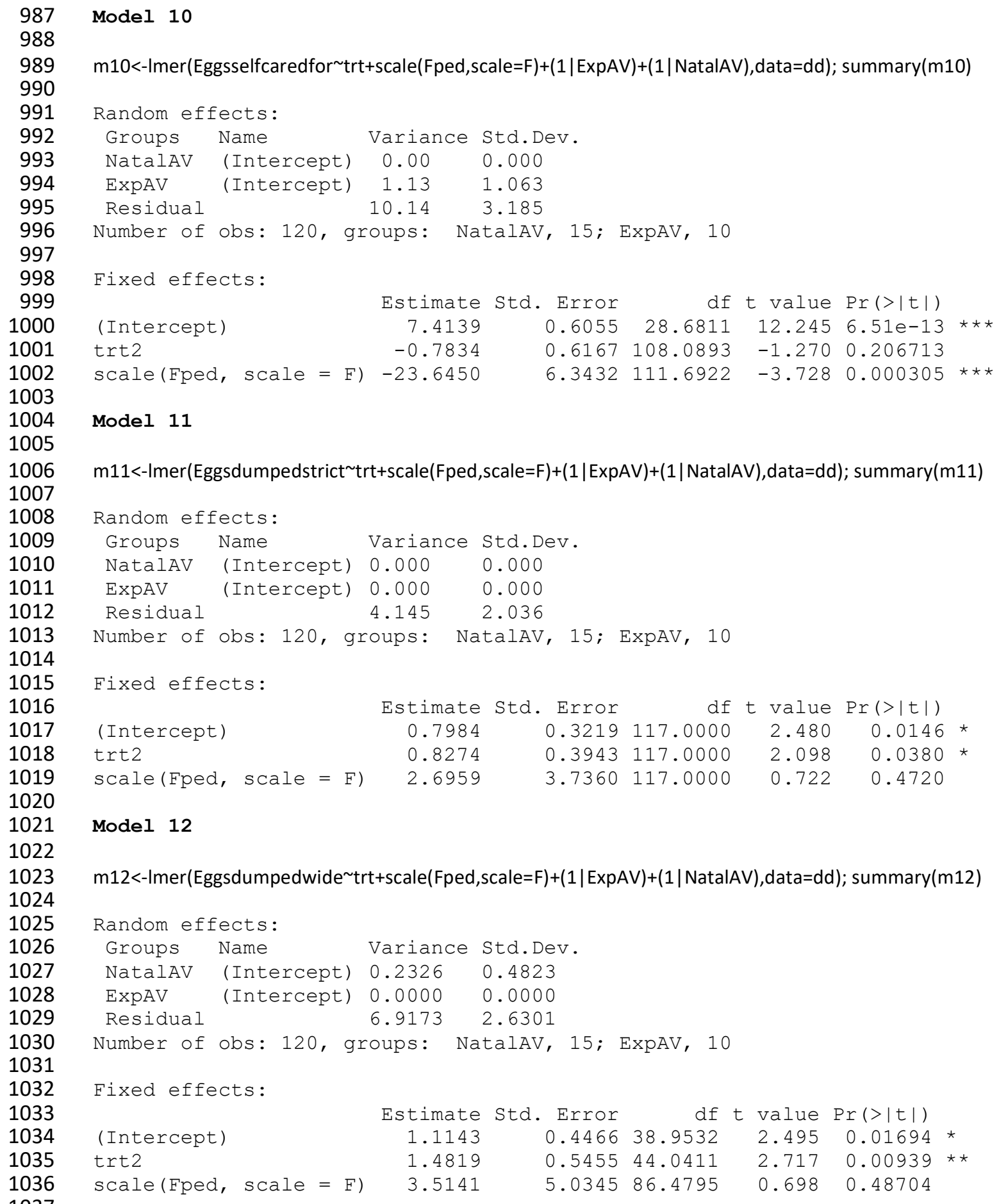

1016

1017

1018

1019

1020

1021

1022

1023

1024

1025

1026

1027

1028

1029

1030

1031

1032

1033

1034

1035

1036

Model 10

m10<-Imer(Eggsselfcaredfor $\sim \operatorname{trt}+$ scale(Fped,scale=F)+(1|ExpAV)+(1| NatalAV), data=dd); summary $(\mathrm{m} 10)$

Random effects:

Groups Name Variance Std.Dev.

NatalAV (Intercept) $0.00 \quad 0.000$

ExpAV (Intercept) $1.13 \quad 1.063$

Residual $10.14 \quad 3.185$

Number of obs: 120, groups: NatalAV, 15; ExpAV, 10

Fixed effects:

$\begin{array}{lrrrrr} & \text { Estimate } & \text { Std. Error } & \text { df } & t \text { value } \operatorname{Pr}(>|t|) \\ \text { (Intercept) } & 7.4139 & 0.6055 & 28.6811 & 12.245 & 6.51 e-13 \\ \text { trt2 } & -0.7834 & 0.6167 & 108.0893 & -1.270 & 0.206713 \\ \text { scale(Eped, scale }=\mathrm{F}) & -23.6450 & 6.3432 & 111.6922 & -3.728 & 0.000305 * * *\end{array}$

\section{Model 11}

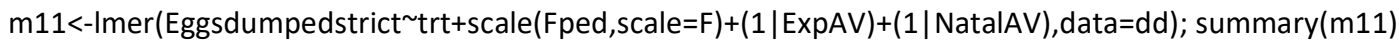

Model 12

m12<-Imer(Eggsdumpedwide ${ }^{2}$ trt+scale(Fped,scale=F)+(1|ExpAV)+(1| NatalAV), data=dd); summary(m12)

Random effects:

Groups Name Variance Std.Dev.

NatalAV (Intercept) $0.2326 \quad 0.4823$

ExpAV (Intercept) $0.0000 \quad 0.0000$

Residual $6.9173 \quad 2.6301$

Number of obs: 120, groups: NatalAV, 15; ExpAV, 10

Fixed effects:

$\begin{array}{llllll}\text { (Intercept) } & 1.1143 & 0.4466 & 38.9532 & 2.495 & 0.01694\end{array}$

$\begin{array}{llllll}\text { trt2 } & 1.4819 & 0.5455 & 44.0411 & 2.717 & 0.00939 * *\end{array}$

scale(Fped, scale $=F) \quad 3.5141 \quad 5.0345 \quad 86.4795 \quad 0.698 \quad 0.48704$

1037 
bioRxiv preprint doi: https://doi.org/10.1101/2021.05.04.442574; this version posted May 4, 2021. The copyright holder for this preprint (which

was not certified by peer review) is the author/funder, who has granted bioRxiv a license to display the preprint in perpetuity. It is made available under aCC-BY 4.0 International license.

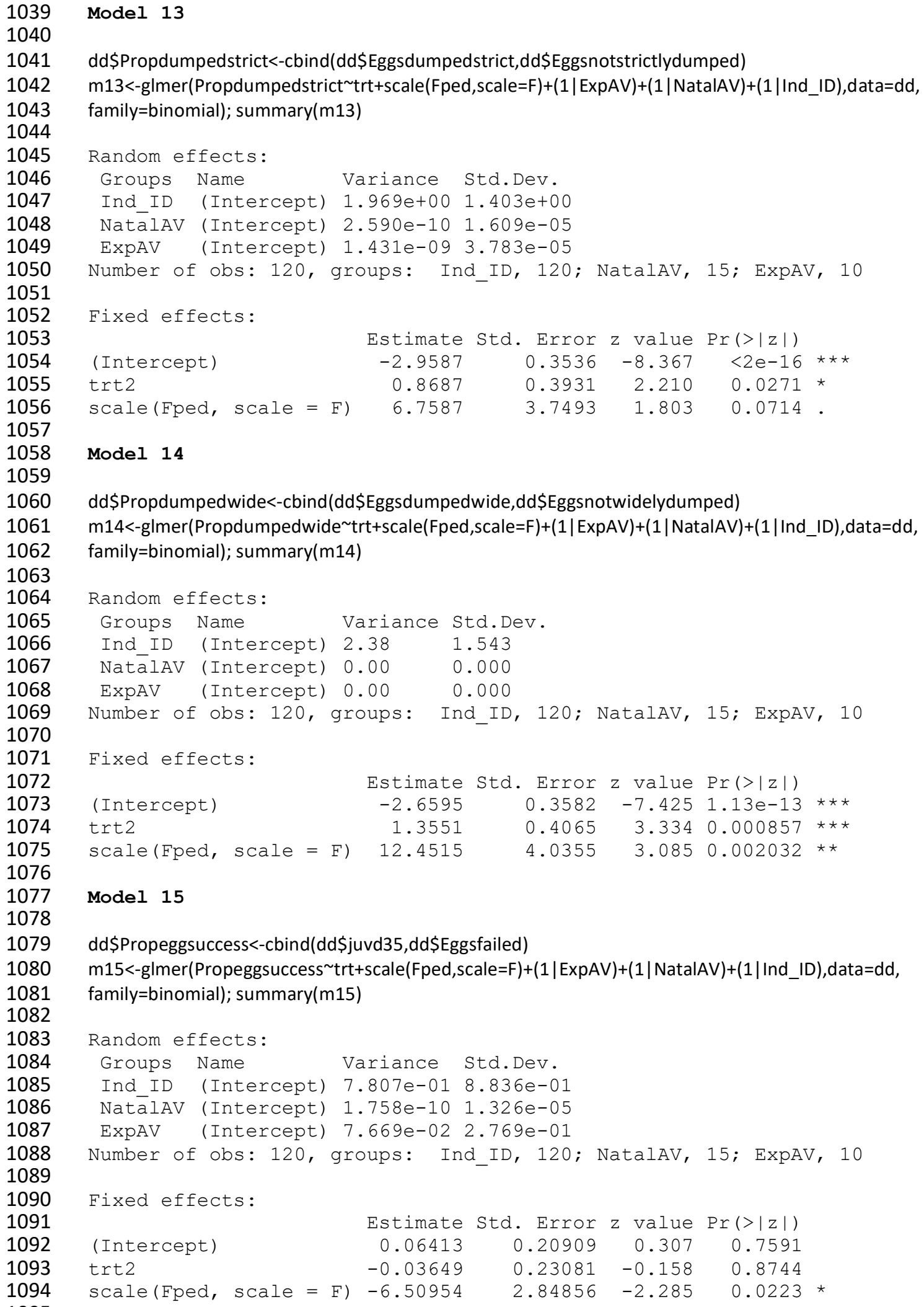

Model 13

dd\$Propdumpedstrict<-cbind(dd\$Eggsdumpedstrict,dd\$Eggsnotstrictlydumped) m13<-gImer(Propdumpedstrict $\sim$ trt+scale(Fped,scale=F)+(1|ExpAV)+(1|NatalAV)+(1|Ind_ID),data=dd, family=binomial); summary $(\mathrm{m} 13)$ 